\title{
Precursors to language development in typically and atypically developing infants and toddlers: the importance of embracing complexity*
}

\author{
DEAN D'SOUZA \\ Centre for Brain $\Xi$ Cognitive Development, Birkbeck, University of London, \\ London, UK, and UCL Institute of Education, University College London, \\ London, UK \\ HANA D'SOUZA \\ Centre for Brain \& Cognitive Development, Birkbeck, University of London, \\ London, UK, and London Down Syndrome Consortium, University College \\ London, London, UK
}

AND

\section{ANNETTE KARMILOFF-SMITH}

Centre for Brain \& Cognitive Development, Birkbeck, University of London, London, UK, and London Down Syndrome Consortium, University College London, London, UK

(Received I6 August 2016-Revised 25 December 2016-Accepted 24 February 2017First published online Io April 2017)

\section{ABSTRACT}

In order to understand how language abilities emerge in typically and atypically developing infants and toddlers, it is important to embrace complexity in development. In this paper, we describe evidence that early language development is an experience-dependent process, shaped by diverse, interconnected, interdependent developmental mechanisms,

[*] D.D. is supported by Autour des Williams, The Waterloo Foundation, and Grant RPG-2015-024 from The Leverhulme Trust. H.D. and A.K-S. are funded by Wellcome Trust Strategic Grant No. $098330 / \mathrm{Z} / \mathrm{I} 2 / \mathrm{Z}$ conferred upon The LonDownS Consortium UK. Address for correspondence: Dean D'Souza, Psychology \& Human Development, UCL Institute of Education, University College London, 25 Woburn Square, London WCıH oAA, United Kingdom. e-mail: dean.dsouza@ymail.com 


$$
\text { D’SOUZA } E T A L \text {. }
$$

processes, and abilities (e.g. statistical learning, sampling, functional specialization, visual attention, social interaction, motor ability). We also present evidence from our studies on neurodevelopmental disorders (e.g. Down syndrome, fragile $\mathrm{X}$ syndrome, Williams syndrome) that variations in these factors significantly contribute to language delay. Finally, we discuss how embracing complexity, which involves integrating data from different domains and levels of description across developmental time, may lead to a better understanding of language development and, critically, lead to more effective interventions for cases when language develops atypically.

\section{INTRODUCTION}

Many researchers express their surprise at the rapid pace and apparent ease with which most infants learn their native language (e.g. Kuhl, 2004). Indeed, it has often been taken as evidence that infants are DESIGNED for the task-a top-down process whereby 'evolution' endows the human neonate with structures DEDICATED TO THE ACQUISITION OF LANGUAGE (Chomsky, I959, I975, I99I; Dehaene-Lambertz \& Spelke, 2015). According to this PREDETERMINED EPIGENESIS perspective, some aspects of language development are independent of other cognitive abilities, and when children struggle to develop language, it is because the 'language part' of the brain is impaired (Pinker, I994). Over the past couple of decades, however, a new account of language development has been championed which treats all linguistic knowledge as an emerging property of complex, experience-driven, self-organizing processes (Hockema \& Smith, 2009; Mareschal, Johnson, Sirois, Spratling, Thomas \& Westermann, 2007; Smith, 2005). According to this PROBABILISTIC 'neuroconstructivist' perspective, language learning is yoked with cognitive development, language emerges from progressive, context-dependent processes that are also associated with non-linguistic learning, and children who struggle to develop language are likely to have domain-general impairments that affect their ability to construct non-linguistic as well as linguistic knowledge. We will discuss evidence in support of these claims; i.e. evidence of early (domain-general) processes through which language abilities emerge in typically and atypically developing infants and toddlers. Our paper is divided into three sections: the first outlines the neuroconstructivist approach we have adopted; the second discusses evidence of early processes (e.g. functional specialization) and mechanisms (e.g. neural plasticity, statistical learning) through which later-developing, higher-level language abilities emerge; and the third considers the theoretical and practical implications of the empirical findings we describe. 
THE NEUROCONSTRUCTIVIST APPROACH TO LANGUAGE

\section{DEVELOPMENT}

Crucial to neuroconstructivism (and other developmental systems approaches ${ }^{\text {I }}$ such as dynamic systems theory) is the concept of control without a controller. On this view, no specific entity-genetic or otherwise-plans or controls development. Instead, developmental processes (including those related to language development) gradually emerge from complex cascades of biological and physical interactions. One way of conceptualizing this is to view development as experience-driven processes that occur within complex biological and ecological systems - and thus as CONSTRAINED by internal and external factors at multiple levels (e.g. genetic, neural, behavioural, societal) and timescales (Mareschal et al., 2007).

Also crucial to neuroconstructivism (and other developmental systems approaches) is the concept of 'interdependence' between different, diverse factors. For example, language development varies as a function of parental input (Hoff, Welsh, Place \& Ribot, 20I4), but parental input varies as a function of the child's language performance (Zampini, Fasolo \& D'Odorico, 2012). The interplay between diverse but InTERDEPENDENT units often generates complex behaviours in living systems. On this view, developmental processes should not be studied in isolation.

Finally, neuroconstructivists (and other developmental systems theorists) argue that development is an EXPERIENCE-DRIVEN process, and that developmental systems (like the human infant) are ADAPTIVE systems (they change in response to their environments, as they act on and learn about them). ${ }^{2}$ On this view, language skills are developed THROUGH learning experiences. Furthermore, the timing of developmental events is likely to

\footnotetext{
${ }^{\mathrm{I}}$ Although developmental systems theory differs from approaches such as dynamic systems theory, connectionism, and neuroconstructivism, the core tenets of developmental systems theory are shared by these three (and other non-nativist) approaches. Therefore, for want of a better term, we (like Ulrich, 2010) use 'developmental systems' as an umbrella term for a group of approaches that view cognitive and motor processes as the emergent functions of a complex stochastic adaptive system. For example, dynamic systems theory and connectionism both seek to explain how emergent (short-term and developmental) dynamics arise from underlying mechanistic dynamics (dynamic systems theorists tend to focus on bodily constraints, connectionists on constrains within the nervous system; Spencer, Thomas, and McClelland, 2009), and neuroconstructivism (which incorporates the connectionist approach [Elman et al., I 996]) seeks to understand how partial representations (information states) in the brain emerge from context-dependent processes and change over developmental time (Mareschal et al., 2007). Although all three approaches converge on problems in developmental psychology from different sides, all three share the central tenet of developmental systems theory: developmental processes emerge from, and are controlled by, a complex web of interactions between diverse, interconnected factors (Blumberg, 20I6).

${ }^{2}$ Having DIVERSE, INTERDEPENDENT parts that ADAPT is what separates 'complex' (social, economic, political, ecological, biological) systems from complicated systems (Miller \& Page, 2007).
} 


$$
\text { D'SOUZA ET } A L \text {. }
$$

be an important constraining factor, because the formation of one function may shape (constrain) how later-developing functions emerge (see D. D’Souza \& Karmiloff-Smith, 20ı6, for discussion).

Why would language skills be developed through learning experiences? Would it not be more advantageous to be born with a language module? Some argue that it is more adaptive to have neural circuits gradually develop over time to ensure that circuitry is appropriately shaped by the specifics of the relevant input (e.g. Bates \& Elman, I993; D. D’Souza \& Karmiloff-Smith, 20 I ; Elman, I 993; Elman, Bates, Johnson, KarmiloffSmith, Parisi \& Plunkett, I 996; Greenough, Black \& Wallace, I987; Johnson, 20I I; Karmiloff-Smith, I 992; Stiles, 2008). In other words, not only may the protracted period of brain development observed in human infants allow late-generated brain structures to emerge (Clancy, Darlington \& Finlay, 2000), it may also provide time for the infant brain to calibrate or adjust its internal operations (connectivity and computations) to the spatial and temporal metrics of the external world (Buzsaki, 2006). A system that adaptively develops in interaction with its environment may also be more robust to perturbation than a system with fixed, predetermined structures and functions (Miller \& Page, 2007). This may explain why an individual's genes can be expressed differently depending on his or her developmental environment (Lickliter, 2016).

The upshot is that neuroconstructivists expect higher-level abilities (such as language) to emerge through a gradual process of adaptation that incorporates mechanisms of change (e.g. neural PLASTICITY) and developmental processes (e.g. progressive FUNCTIONAL SPECIALIZATION) across different (but interconnected) levels and domains. 'Plasticity' refers to the process by which neural connectivity and circuitry change as a function of experience. It comprises different mechanisms, occurs on different levels and timescales (from the nearly immediate local effects of Hebbian plasticity to gradual large-scale reorganization of the brain; Power \& Schlaggar, 2016), and is associated with functional changes that include learning and memory. 'Functional specialization' is the concept that activity-dependent interactions between different interdependent factors (e.g. neural plasticity, sensory input) hone the functions and response properties of neural networks such that their activity becomes restricted to a narrower set of circumstances (Johnson, 20 I I). For example, neural networks that activate in response to, and can discriminate between, human infant, human adult, and monkey faces may - after extensive experience with only human adult faces become increasingly tuned to processing human adult face stimuli and lose the ability to discriminate well between human infant or monkey face stimuli (Macchi Cassia, Bulf, Quadrelli \& Proietti, 20 1 4; Pascalis, de Haan \& Nelson, 2002). Thus, at the behavioural level, developmental systems approaches expect highly constrained, highly organized, structured activity to emerge 
gradually from widespread, uncoordinated, spontaneous activity; at the brain level, they expect increased neural tuning (specialization) in response to a given stimulus or set of task demands (Johnson, 20II). Indeed, this developmental process - i.e. functional specialization - has been identified in several domains, including face perception (Pascalis et al., 2005), motor ability (H. D’Souza, Cowie, Karmiloff-Smith \& Bremner, 20г6), and - as we discuss below - language ability.

\section{SPECIALIZATION AS AN ACTIVE PROCESS}

However, progressive specialization is not a passive process; it requires the infant to calibrate its internal operations to the external world by actively exploring (selecting, acting on) and sampling it (Buzsaki, 2006). If the infant lacks the cognitive tools to intelligently explore or sample the environment, or is exposed to an atypical or restricted environment that hampers exploration, then this will constrain the process of specialization and the infant is more likely to develop atypically (Johnson, Jones \& Gliga, 20 I 5). In other words, infants adapt to their environment, including the language environment, by exploring it. Before they can acquire language, they must be able to sample and extract structure from the external world, as well as learn what aspects of the environment are relevant, i.e. worth directing their attention towards. For example, infants when lying on their back must redirect their attention from, say, the surface of a featureless ceiling to sample a novel talking face, and learn to extract patterns (units of speech) from the continuous streams of sound that they hear. They must also learn what aspects of their environment to focus on. For instance, if a preverbal infant were to focus their attention only on changes in pitch, then they would miss important distributional (and other acoustic) cues. Even if the preverbal infant were to appropriately select and act on the environment, such as orienting away from a ceiling towards a speaking face to sample important audiovisual speech information, he or she would also need to process that information appropriately (i.e. learn from it) or risk specializing atypically. These overlapping basic-level neurocognitive processes and mechanisms-SAMPLING (gathering information), LEARNING (extracting structure and integrating information), and ATTENTION (selecting information)-are important precursors to language acquisition, and the topics of the following three subsections.

\section{Sampling}

Because progressive specialization reflects changes in neural connectivity and the response properties of different neurons over developmental time (Johnson, 20II), and because it is an experience-dependent process (i.e. adaptive systems require input), the process of sampling the environment affects functional plasticity and the timing of developmental processes 


$$
\text { D’SOUZA } E T A L \text {. }
$$

(Benasich, Choudhury, Realpe-Bonilla \& Roesler, 2014; Frankenhuis \& Panchanathan, 20I Ia, 20I Ib). For example, an absence of visual input can prolong the critical period during which visual information may shape certain structures (e.g. ocular dominance columns) in primary visual cortex (Mower, Caplan, Christen \& Duffy, r 985). In human infants, inter-individual variation in sampling can occur as a result of (i) variation in the external environment, (ii) differences between infants' 'internal' environments (interactions between genes and their molecular and cellular environments), and (iii) interactions between the infant and external environment. We discuss all three constraints in detail below, using examples from the literature on bilingualism (variation in the external world), neurodevelopmental disorders (internal differences), and how having a neurodevelopmental disorder interacts with parenting (internal-external interaction).

Differences in sampling due to the external environment. Because sampling is a stochastic process (events can be statistically analyzed but not precisely predicted), Frankenhuis and Panchanathan (20I Ib) hypothesize that functional specialization is likely to vary as a function of sampling behaviour. Specifically, infants who develop in highly variable environments are likely to specialize later in development than infants who develop in less variable ones. This is because sampling a less variable environment would allow the infant to quickly generate confident estimates, build accurate models of the external world, and successfully anticipate future events. By contrast, infants who develop in more variable environments may require more samples to generate confident estimates and thus more time to specialize to their environments.

In the language domain, functional specialization starts early in life. For example, human neonates are sensitive to a wide range of phonological contrasts, both native and non-native (e.g. Bertoncini, Bijeljac-Babic, Blumstein \& Mehler, I987; Eimas, Siqueland, Jusczyk \& Vigorito, I97ı; Streeter, I976). However, between 6 and 12 months of age, their sensitivity to non-native contrasts declines, while their ability to discriminate between contrasts in their native language improves (Kuhl, Stevens, Hayashi, Deguchi, Kiritani \& Iverson, 2006; Werker \& Tees, I 984; Werker, Yeung \& Yoshida, 2012). In other words, the infant brain becomes progressively sELECTIVE to its native language. This process of specialization, which involves neural commitment and thus co-occurs with a corresponding reduction in plasticity, increases the fit between infants and their specific language environment (Kuhl, Conboy, Coffey-Corina, Padden, Rivera-Gaxiola \& Nelson, 2008). But what would happen if a child were exposed to a multilingual environment? It is likely that, within the same time frame, the child would be provided with fewer samples from each language than a child raised in a monolingual environment would receive from its one language (Byers-Heinlein \& Fennell, 20I4).

$$
596
$$


Moreover, the presence of two or more languages would likely make the multilingual environment more variable (e.g. increased phonemic variability) than the monolingual environment. Although the effects of exposure to a more variable language environment can be offset by use of predictive cues (e.g. interlocutor identity; Martin, Molnar \& Carreiras, 20 r6), for many children, language input from two different languages may originate in the same person, the same environment, and even the same sentence (Byers-Heinlein, 20I3). Furthermore, bilingual input may be less accurate (and thus less consistent) than monolingual input. Bosch and Ramon-Casas (20I I) analyzed speech recordings from a group of Catalan-Spanish bilingual mothers who reported speaking predominantly Catalan at home. They found that the mothers who had been raised in Spanish-Catalan homes or Spanish-speaking homes with early exposure to Catalan made significantly more errors when producing words that contain the Catalan $/ \mathrm{e} /-/ \epsilon /$ contrast (which is not present in Spanish) than the mothers who had been raised in Catalan-speaking homes. These additional constraints (e.g. more variability, less consistency) could make sampling the language environment more challenging for bilingual infants, which may prolong the process of functional specialization in the language domain. Indeed, emerging evidence is consistent with this proposal. Pi Casaus (2015) has found that bilingual infants maintain the capacity to discriminate non-native consonants for six months longer than monolingual controls. Moreover, Sebastián-Gallés, Albareda-Castellot, Weikum, and Werker (2012) found that 8-month-old Spanish-Catalan bilinguals, but not 8-month-old Catalan or Spanish monolinguals, can visually discriminate English from French when watching silent video clips of French-English bilingual speakers reciting sentences in French or English. Although children younger than 8 months were not tested, this suggests that bilinguals maintain their sensitivity to non-native languages for longer. However, neither monolinguals nor bilinguals were able to discriminate between unfamiliar languages in adulthood (Werker, I 986). This indicates that specialization in bilinguals is initially protracted, but leads to a similar adult state. Yet even this state may be different in these two populations. Tremblay and Sabourin (2012) showed that although bilingual adults do not differ in their ability to discriminate non-native contrasts from monolingual controls, they show an enhanced ability to learn them. This suggests that the adult bilingual brain retains some of its early plasticity (i.e. it is extra-sensitive to changes in the environment), perhaps as a consequence of a slower rate of specialization. ${ }^{3}$ Thus, we argue that language context may

3 Interestingly, Bosch and Sebastián-Gallés (2003) found that bilingual Spanish-Catalan infants could discriminate a contrast native to Catalan at 4 months and 12 months, but not at 8 months. This $\mathrm{U}$-shaped developmental pattern is difficult to explain. However, 


$$
\text { D'SOUZA ET } A L \text {. }
$$

affect brain and cognitive development via differences in the frequency, variability, and consistency of linguistic input. It is important to note, however, that we are not claiming that differences in neural plasticity or functional specialization are necessarily negative; differences in plasticity/ specialization between bilinguals and monolinguals are likely to be adaptive, increasing the fit between the infant and its environment (D. D'Souza \& H. D'Souza, 2016). They may even be the source of a purported cognitive advantage in bilinguals (D. D'Souza \& H. D'Souza, 20ı 6).4

Differences in sampling due to the internal environment. As described above, the ability to discriminate contrasts in the native language improves over developmental time (Kuhl et al., 2006), while sensitivity to non-native contrasts declines (Werker \& Tees, I984; Werker et al., 2012). This specialization for native language increases the fit between infants and the environment. However, infants demonstrate considerable variability in their ability to adapt to the environment. Moreover, these early individual differences are associated with later developmental outcomes. Specifically, infants who show more specialization for their native language (e.g. better native, and/or worse non-native, phonetic perception skills) have on average better language outcomes as toddlers (Kuhl, Conboy, Padden, Nelson \& Pruitt, 2005; Kuhl et al., 2008; Tsao, Liu \& Kuhl, 2004). Assuming that there were no major differences in the amount and quality of the linguistic input that the participants received, we could draw the conclusion that later emerging language abilities are at least partly constrained by individual differences in the ability to select or process environmental input.

If individual differences in sampling constrain development even in typically developing children, then might alterations in sampling in atypically developing populations affect developmental processes such as specialization to an even greater extent? For example, there is some evidence that neurophysiological responses to speech input are initially diffuse (widespread and bilateral) in typically developing (TD) children

\footnotetext{
progressive specialization is likely to include changes between neural circuits as well as within neural circuits (Johnson, 20I I). The U-shaped pattern may therefore reflect not a complete loss and subsequent gain of an ability to discriminate the native contrast, but rather a reorganization of neural connectivity at around 8 months that resulted in a temporary reduction in sensitivity to the contrast. By contrast (and as expected), monolingual Catalan infants could discriminate the contrast at all three ages, while monolingual Spanish infants could discriminate the contrast only at 4 months.

${ }^{4}$ We are currently testing the hypothesis that experience-driven adaptations to more variable language input involve changes to basic learning mechanisms in infants that give rise to a purported cognitive advantage (e.g., task-switching, cognitive flexibility): <https://www. researchgate.net/project/Raising-bilingual-children-the-effects-of-exposure-to-a-bilingualenvironment-on-cognitive-development-in-infants>.
} 
and only gradually become more focal (e.g. left hemisphere dominant) and differentiated (with regions fractionating and becoming more selectively activated) over developmental time (Brauer \& Friederici, 2007; Minagawa-Kawai, Mori, Naoi \& Kojima, 2007; but see Brown, Petersen \& Schlaggar, 2006, for critical discussion). By contrast, twenty-four toddlers with autism spectrum disorder (ASD) showed more diffuse patterns of activation in responses to speech input than twenty TD controls matched on chronological age (Coffey-Corina, Padden \& Kuhl, 2008). Moreover, when the toddlers with ASD were divided into 'high' and 'low' functioning subgroups (by median split of Autism Diagnostic Observation Schedule social scores; Lord et al., I989), the twelve low functioning toddlers with ASD showed more diffuse patterns of activation than the twelve high functioning toddlers with ASD (Coffey-Corina et al., 2008). Johnson et al. (2015) propose that synaptic dysfunction in ASD (e.g. perturbed synaptogenesis; Bourgeron, 2009; Gilman, Iossifov, Levy, Ronemus, Wigler \& Vitkup, 20I I Zoghbi, 2003) results in increased neural noise and poor sampling of the environment (reduced fidelity), which leads to prolonged specialization plus excessive plasticity and hence developmental delay. Indeed, poor evoked (neural) response reliability (i.e. less consistency across trials), yielding weaker signal-to-noise ratios in visual, auditory, and somatosensory systems, has been identified in fourteen adults with ASD relative to fourteen TD controls matched on chronological age and IQ (Dinstein, Heeger, Lorenzi, Minshew, Malach \& Behrmann, 20I2). A similar theory of autism suggests that excessive neuronal information processing in local circuits (leading to hyper-perception, hyper-attention, hyper-memory, etc.) renders the world uncomfortably intense for individuals with the disorder, leading to social and environmental withdrawal (Markram, Rinaldi \& Markram, 2007; see also Rubenstein \& Merzenich, 2003, and Simmons, Robertson, McKay, Toal, McAleer \& Pollick, 2009, for similar theories). This would also result in poor sampling of the environment. Although this has not yet been directly tested in toddlers with ASD, atypical patterns of brain activity (e.g. reduced gamma phase-locking) in children with ASD look similar to patterns of brain activity in rats prenatally exposed to valproic acid (Gandal, Edgar, Ehrlichman, Mehta, Roberts \& Siegel, 2010), a chemical compound that causes hyper-reactivity, hyper-connectivity, and hyper-plasticity of glutamatergic synapses in local cortical microcircuitry (Markram et al., 2007), hinting at an association between developmental delay and excessive plasticity. Furthermore, infants who develop ASD attend less to people and their activities from 6 months of age, and while their social-communication skills are indistinguishable from those of TD infants at 6 months, clear differences emerge by 12 months (see Jones, Gliga, Bedford, Charman \& Johnson, 2014, for a review). 


$$
\text { D'SOUZA ET } A L \text {. }
$$

ASD is not the only disorder for which synaptic dysfunction has been attributed, however. In fact, a number of other neurodevelopmental disorders also show widespread abnormalities in synaptic function and plasticity (Blanpied \& Ehlers, 2004; Zoghbi, 2003). For example, dendritic spine abnormalities (which result in synaptic dysfunction; Nimchinsky, Sabatini \& Svoboda, 2002) have been identified in Down, fragile X, Patau, Rett, and Williams syndromes (Chailangkarn et al., 20г6; Irwin, Galvez \& Greenough, 2000; Kaufmann \& Moser, 2000). At the same time, functional specialization in one or more domains may be atypical in these disorders. For example, whereas music (vs. noise or rest) elicits reliable, robust, and focal activations in superior and middle parts of the temporal lobe in TD adults, it elicits highly variable and diffuse activation in adults with Williams syndrome that involves regions in the amygdala, cerebellum, and brainstem (Levitin et al., 2003).

Although more evidence is needed to establish a link between synaptic abnormalities and protracted or atypical specialization, it is highly probable that synaptic disturbances affect development. This is because synapses enable neurons to communicate with one another. They are not fixed; rather, they are modifiable, constantly being created, pruned, and altered throughout the lifespan. Although the development of neuronal circuitry is constrained by epigenetic activity, the size, shape, number, and pattern of synaptic connections are governed by experience (Fiala, Spacek \& Harris, 2002). Synaptic dysfunction could lead to sparser and less reliable sampling of environment, and hence a worse signal-to-noise ratio, which in turn may result in protracted plasticity and atypical specialization of function (Rubenstein \& Merzenich, 2003). Therefore, because individuals with neurodevelopmental disorders present with synaptic abnormalities, they may have difficulty sampling their environment efficiently, and hence present with prolonged or atypical specialization early in development.

Differences in sampling due to interactions between the external and internal environments. Abnormal specialization in individuals with a neurodevelopmental disorder may not just be the result of individual differences at the genetic level, however. Atypically developing children also develop within atypical environments. This can result from straightforward interactions; for example, a child with Williams syndrome who has difficulty reading may spend less time reading and thus receive less linguistic input (fewer samples) than a TD child. But it can also result from subtler interactions. For example, we have argued that the "moment that a parent is informed that their child has a genetic disorder, the parent's behaviour subtly changes ... [and] as a result, the baby's responses within the dyadic interaction will also be subtly modified" (Karmiloff-Smith, D'Souza, et al., 2012, p. I7263). In other words, a 
change at the genetic level may induce changes in the environment, which may have compounding effects on brain and cognitive development, which will affect gene expression and other gene-environment interactions. We have, for instance, observed that "parents of infants/toddlers with genetic syndromes often find it difficult (compared with parents of TD infants) to allow their atypically developing offspring to freely mouth objects to explore their properties with the sensitive nerve endings in the mouth or crawl/walk uninhibited around the laboratory to fully discover their environment" (Karmiloff-Smith, D’Souza, et al., 2012, pp. I7263-17264). Although the reticence of parents with vulnerable children is understandable, it will likely result in a less richly explored, less sampled environment.

Another example of how interaction between external and internal environments constrains sampling comes from two studies on Down syndrome (DS). Whereas parents of TD children often use basic-level category terms to label objects in naming (e.g. 'bird' for magpie), Cardoso-Martins and Mervis ( 1985 ) found that the parents of five children with DS were more likely to use the precise names of objects (e.g. 'magpie'). This difference between parental linguistic inputs may stem from the fear that a child with a neurodevelopmental disorder may never learn the correct names for objects. But different input may have deleterious effects. For instance, Karmiloff-Smith, D'Souza, et al. (2012) suggest that initial overgeneralization encourages category formation (e.g. by calling different animals 'bird', the child starts to create an implicit animal category) and children with neurodevelopmental disorders have difficulty with category formation. It is important to note, however, that Cardoso-Martins and Mervis (I985) studied only five child-mother dyads with DS, and also they did not establish a causal relationship between maternal labelling behaviours and children's language development (see Rondal \& Docquier, 2006, for a critical review). Nevertheless, unconscious assumptions about what an atypical child can and cannot learn may lead parents to provide less variation in linguistic input (fewer samples) and thus a more impoverished linguistic environment. Indeed, a more recent study provides evidence that maternal input addressed to fourteen 24-month-olds with DS is simpler (contains fewer function words and more onomatopoeic words/routines) than that addressed to twenty-eight TD controls matched on lexical skills (Zampini et al., 2012). Although it remains to be investigated whether children with DS may in fact benefit more from simpler input, the study demonstrates how interaction between external and internal environments alters the frequency and quality of linguistic input, which may constrain development by changing the learning environment. Furthermore, because the cognitive and linguistic profiles of children with neurodevelopmental disorders are often uneven 


$$
\text { D’SOUZA } E T A L \text {. }
$$

(e.g. Karmiloff-Smith, Broadbent, et al., 2012), genetic vulnerabilities may make it more difficult for caregivers to accurately assess their child's developmental level and adjust their expectations and input accordingly. This may especially be the case because neurodevelopmental disorders often affect expressive language more than receptive language in infants/ toddlers (e.g. D. D’Souza, 20I4), and parents often tell us that expressive language is easier to assess than receptive language, which hints at the possibility that they are underestimating their child's receptive language ability.

\section{Learning}

Accumulating samples is essential for adaptive behaviour, because an infant can only adapt to the external world by gathering information about it. However, for the information to be useful, the infant must also be able to understand or extract structure from the samples. For example, they must learn to extract patterns (units of speech) from the continuous streams of sound they hear. In the following sections, we discuss two important learning mechanisms in infancy: (i) habituation and (ii) statistical learning.

Habituation. Arguably, the most basic learning mechanism available to the human infant for proactive exploration is habituation. Habituation is an adaptive process by which the infant familiarizes itself with, and gradually builds up an internal representation of, an external stimulus (Rankin et al., 2009; Sokolov, I963). Over repeated successive presentations of the stimulus, the internal representation comes to represent the stimulation increasingly well, the stimulus becomes less relevant to the infant, and novelty-seeking behaviour is triggered (see Sirois \& Mareschal, 2004, for a biologically plausible computation model of habituation to the familiar and novelty preference). How might this relate to language? Habituation may be a core mechanism by which the perinatal brain discriminates languages and starts specializing to its language environment (Werker \& Byers-Heinlein, 2008). Habituation measures are also believed to index quality or speed of cognitive processing in infants (Colombo \& Mitchell, I990; Colombo, Shaddy, Richman, Maikranz \& Blaga, 2004), and cognitive processes are critical for learning-including word learning. Indeed, a large body of evidence suggests that habituation patterns in infants predict developmental outcomes in language comprehension and production (Ruddy \& Bornstein, I982; Tamis-LeMonda \& Bornstein, I 989), as well as general intelligence (Bornstein \& Sigman, I 986; Kavšek, 2004; McCall \& Carriger, I 993; Rose, Slater \& Perry, I986). For example, in the visual domain, Tamis-LeMonda and Bornstein (I989) presented thirty-seven typically developing 5-month-olds with a series of face stimuli. The mean duration of the infant's first two looks constituted a 
baseline, and stimulus presentations continued until the infant had reached a habituation criterion of two consecutive looks each less than $50 \%$ of that baseline. The researchers found that shorter baselines (the start level of habituation), steeper slopes (the decline in attention), and lower decrement scores (the asymptote of habituation) predicted better language comprehension (the number of words flexibly understood across contexts) at 13 months. In the auditory domain, Choudhury and Benasich (20 I I) presented twenty-eight TD 6 -month-olds with consecutive pairs of tones, of which $85 \%$ were 'standard' ı I $00-300 \mathrm{~Hz}$ pairs. In this auditory oddball paradigm, the auditory system starts to habituate to the consecutively presented standards, a process that is punctuated at random intervals by presentation of the infrequent deviant and resultant 'mismatch' brain response. Auditory evoked potentials (AEPs) predicted language abilities at 36 and 48 months of age. Specifically, infants with larger and sharper (more transient) 'mismatch' AEPs in response to the deviant stimuli had better receptive and expressive language scores (measured using the Preschool Language Scale [Zimmerman, Steiner, \& Pond, I 992] and Clinical Evaluation of Language Fundamentals [Wiig, Secord, \& Semel, I 992]).

Individual differences in habituation mechanisms may therefore constrain language development. This may also be the case for children with neurodevelopmental disorders. Although no study has hitherto reported an association between variation in habituation and language development in atypically developing children, Guiraud et al. (201 I) found that auditory evoked potentials to repeated (non-speech) sounds decrease over time in twenty-one TD infants but not in thirty-five infants at high risk of developing autism, which indicates impaired habituation. Furthermore, using an auditory oddball paradigm similar to the one described above, D. D'Souza (2014) found that AEPs to repeated (speech) sounds are also atypical in Down syndrome, fragile $\mathrm{X}$ syndrome (FXS), and Williams syndrome (WS): mismatch AEPs in response to deviant speech sounds were identified in TD infants $(N=2 \mathrm{I})$ but attenuated in infants at high risk of developing autism $\left(N=3_{3}\right)$ ) or with $\mathrm{DS}(N=4 \mathrm{I})$, FXS $(N=\mathrm{I} 0)$, or WS $(N=33)$. Although we have yet to relate these brain data to the language data we collected from these children, the neurocognitive processes indexed by mismatch AERs trigger novelty-seeking attentional processes, such as the ' $\mathrm{P}_{3}$ ' attentional orienting brain response, which we know (i) is atypical in these particular children, and (ii) is significantly correlated with vocabulary size (especially in fragile $\mathrm{X}$ syndrome; see section below on 'Reallocating attention' for details on the link between the $\mathrm{P}_{3}$ and language ability). Finding the optimal balance between building useful representations of the external world and exploring it is critical for adaptive behaviour. If children with neurodevelopmental 


$$
\text { D'SOUZA ET } A L \text {. }
$$

disorders require more time to consolidate their knowledge (due to impaired habituation mechanisms), then they will have less time to proactively explore and sample new information from their environment, which may also affect their language development. 5

Statistical learning. Another learning mechanism is STATISTICAL LEARNING, the process by which infants identify, and track over time, patterns in sensory information. These patterns range from frequency count ('there are more sweets in the blue box than in the red one'), through frequency of co-occurrence ('mum often appears when I cry'), to conditional probability ('bed-time is more likely to follow bath-time than dinner-time') (Romberg \& Saffran, 2010). They also differ in complexity (e.g. simple geometric shapes vs. complex faces) and concreteness (e.g. changes in pitch vs. syntactic categories) (Romberg \& Saffran, 2010). Importantly for the field of language development, Saffran, Aslin, and Newport (1996) demonstrated that 8-month-olds could discern recurrent syllable sequences from syllable strings spanning word boundaries by attending to statistical regularities called TRANSITIONAL PROBABILITIEs (the conditional probability of $Y$ given $X$ in the sequence $X Y$ ). Since publication of that seminal paper, researchers have discovered that even sleeping neonates are sensitive to the statistical structure of fluent speech (Teinonen, Fellman, Näätänen, Alku \& Huotilainen, 2009) and that many different types of sequences can be learned (e.g. AcB, where $\mathrm{c}$ is an element that can vary; Hsu \& Bishop, 2010).

Although Saffran et al. ( I 996) argued that statistical learning is the process through which infants segment words from fluent speech (a critical step in language acquisition), they had in fact only demonstrated that 8-month-olds could distinguish between sound sequences of varying internal coherence (high vs. low transitional probability). Questions remained unanswered, which prompted further research. For example, how do infants go from discriminating sound sequences of varying internal coherence to identifying words? Does their sensitivity to different levels of speech input (phonemes, syllables, onset, rime, lexical stress, prosody, grammatical structure, semantics, etc.) change over developmental time? What process determines which statistics are used (frequency count, frequency of co-occurrence, mutual information, etc.)? It turns out that infants actually use a range of mechanisms to combine and extract structure from multiple sources of information - which is why attentional processes (see 'The role of attention in sampling' section below) are so important (Kirkham, Slemmer \& Johnson, 2002). For

\footnotetext{
5 An important part of habituation (and other learning mechanisms) is memory, which is also impaired in infants with neurodevelopmental disorders (e.g., Down syndrome; Edgin, 2013).
} 
example, by 7-8 months, infants use both prosodic information and statistical information (e.g. transitional probabilities) to segment the speech stream, but give more weight to the former (Echols, Crowhurst \& Childers, I997; Jusczyk, Houston \& Newsome, r 999; Morgan \& Saffran, I 995). In other words, they segment speech at the boundary before strong syllables, and group together syllables that frequently co-occur as long as they do not cross a prosodically defined boundary. By 10.5 months, the weighting changes, with more emphasis on distributional, allophonic, and phonotactic cues than on prosody. Furthermore, Graf Estes, Evans, Alibali, and Saffran (2007) found that I7-month-olds use distributional information to create internal representations, which serve as 'candidate words' that they can later map onto objects. In other words, children do not merely track patterns in the speech stream; they use the statistical information to learn words and word meanings (Lany \& Saffran, 2010; Saffran \& Wilson, 2003; Sahni, Seidenberg \& Saffran, 2010; Thiessen \& Saffran, 2007).

What about statistical learning in atypical populations? This question has rarely been examined to date. One study found that a group of nineteen toddlers with Williams syndrome (mean chronological age was 33 months; mean mental age was i 9 months) had difficulty with speech segmentation; they could detect bisyllabic words with a strong-weak stress pattern (e.g. doctor) but not a weak-strong one (e.g. guitar)-even though a typically developing infant can do this by 10.5 months (Nazzi, Paterson \& Karmiloff-Smith, 2003). A more recent paper found that a group of eighteen 8- to 20-month-old children with WS successfully demonstrated statistical learning of transitional probabilities in continuous speech (Cashon, Ha, Estes, Saffran \& Mervis, 2016). However, the mean chronological age of the children was I 5.5 months and the study did not include a control group, so it is impossible to know whether statistical learning was typical or atypical (i.e. whether onset of statistical learning was developmentally late and/or whether rate of development was slow). More research is clearly needed in this domain.

\section{The role of attention in sampling}

Another problem that individuals with neurodevelopmental disorders may have-apart from extracting structure - is inadequate sampling as a result of not focusing on relevant aspects of the environment. Previously, we highlighted the need for infants to redirect their attention away from, say, featureless ceilings to speaking faces, or for infants to focus on changes in speech sounds rather than pitch (see above). If infants fail to allocate attention appropriately, then they may miss important social cues and linguistic input, which would make it harder for them to develop 


$$
\text { D'SOUZA ET AL. }
$$

language. In the following two subsections, we review evidence of two important attentional precursors to language acquisition: the ability to (i) reallocate attention, and (ii) attend to multiple sources of information and integrate them.

Reallocating attention. Typically developing infants adapt to their environment in part by learning how to shift the focus of their processing resources to the relevant aspects of a scene (Kanwisher \& Wojciulik, 2000). This is important because it allows detailed analysis of relevant stimuli, while filtering out irrelevant (distracting) stimuli. A child who can flexibly select and attend to things in their environment, and use this ability to guide action, will interact with (and thus experience) the world differently than a child with an attentional deficit. As a consequence, irregularities in attention may have deleterious effects on development.

For example, some evidence suggests that an important attentional precursor of language development is TRIADIC INTERACTION, which is when a parent uses eye-contact and eye-gaze to direct their child's focus of attention to an object or event of interest (Brooks \& Meltzoff, 2005; Morales, Mundy \& Rojas, ı 998; Mundy \& Gomes, I998; Trevarthen \& Hubley, I978; but see Yu \& Smith, 20I3, for evidence that toddlers are more likely to follow their parent's hands than eyes, and that the interaction is between equals rather than the parent taking the lead). Triadic interaction requires the infant to orient to speech sounds and flexibly shift their attentional focus between visual stimuli (the caregiver and an object of interest). TD infants learn to do this from as early as 3 months of age, developing robust triadic interaction skills by 12 months (Striano \& Stahl, 2005). However, the literature hints that triadic interaction is impaired in at least some neurodevelopmental disorders. For example, Laing et al. (2002) found that a group of eleven toddlers with Williams syndrome (and a mean age of 29 months) followed pointing behaviour less frequently than a group of eleven TD infants matched on mental age (I3 months). Also, whereas pointing precedes speech production and is predictive of early vocabulary development in TD (Bates, Benigni, Bretherton, Camaioni \& Volterra, I979; Butterworth, I 998), it appears after speech production in WS (Mervis \& Bertrand, I997). In a longitudinal study of ten children with WS, Mervis and Bertrand found that the children did not produce referential pointing gestures until well after the onset of language. Furthermore, they did not respond appropriately to their mothers' pointing gestures, even though they were beginning to speak referentially. Directing and following attention via pointing may therefore be under-utilized in WS. It is also possible that poor saccadic control in children with WS (Brown, Johnson, Paterson, Gilmore, Longhi \& Karmiloff-Smith, 2003) affects gaze following (and hence may negatively impact language development).

\section{6}


Although preliminary eye-tracking data from our lab tentatively suggest that a group of nine 2- to 3-year-olds with WS (and a mean age of 34 months and a mean verbal age of 19 months) MAY be able to follow gaze (unpublished observations), gaze following and its relationship to word learning has yet to be investigated in younger children with WS.

To further investigate how attention and language are related, we compared attentional processes, and their relation to language ability, in TD I 5-month-olds $(N=27)$ with chronological- and mental-age-matched infants/toddlers who either had a neurodevelopmental disorder (Down syndrome $[N=45]$, fragile $\mathrm{X}$ syndrome $\left[N=\mathrm{I}_{5}\right]$, Williams syndrome $[N=37])$ or were at high risk of developing autism $(N=5 \mathrm{I})$ (D. D'Souza, 2014). The study included an eye-tracking version of the GAP-OVERLAP TASK (adapted from Atkinson, Hood, Braddick \& Wattam-Bell, I 988), which measures how quickly the participant DISENGAGES from, SHIFTS to, and Engages with visual stimuli. These children also participated in a passive auditory oddball experiment, where continuous electroencephalogram (EEG) was recorded from the infant while speech sounds $(70 \%$ standards, I $5 \%$ speech deviants, I $5 \%$ pitch deviants) were presented in the background (one every $700 \mathrm{~ms}$ ). We found that the chronological- and mentalage-matched children with DS were slower than the TD controls at disengaging attention from a visual stimulus, while the chronological- (but not older mental-) age-matched infants with WS were slower at engaging (or fully processing) a visual stimulus. Also, both chronological- and mental-age-matched children with WS were slower at shifting visual attention. Moreover, the electrophysiological response to speech sounds was abnormal in all the atypically developing groups (and in the 'at high risk of developing autism' group) in one or more stages of processing: encoding auditory stimuli, discriminating between speech sounds, and orienting to changes in speech sounds (vs. pitch). ${ }^{6}$ For example, the electrophysiological response that typically indexes 'sound encoding' did not significantly differ between stimulus types (standards, speech deviants, pitch deviants) in any of the groups - except the TD control group.

How did the attentional measures we collected relate to language ability? Across all groups, infants/toddlers who were better at disengaging visual attention and/or showed a larger attentional orienting brain response to changes in speech sounds had relatively large vocabularies (though it is important to note that the [statistically significant, medium-sized] effect of disengagement was largely driven by the TD control group, unlike the [medium-sized] effect of orienting which was highly significant across all

\footnotetext{
6 Stages of processing were not directly tested in this particular study but were inferred from the event-related potential (ERP) components established in previous research (see D. D'Souza, 2014, for details).
} 


$$
\text { D'SOUZA ET } A L \text {. }
$$

groups). Between-group differences were also identified. For example, the toddlers with FXS (mean chronological age $=33$ months) who had a relatively small orienting response (measured using the event-related potential technique) had a significantly smaller expressive vocabulary size (equivalent only to TD 5-month-olds) than those who had a relatively large orienting response (expressive language equivalent to TD I3-month-olds). This relationship did not reach significance in the DS group. However, for children with DS (mean chronological age $=28$ months), those who were relatively poor at disengaging attention had a significantly smaller expressive vocabulary size (equivalent only to TD I I-month-olds) than those who were relatively good at disengaging attention (expressive language equivalent to TD iz-month-olds). This relationship did not reach significance in the FXS group. Together, these data suggest at least two mechanisms for acquiring good language skills, one more relevant to FXS (social orienting), and one more relevant to DS (visual disengagement). We speculate that disengaging and shifting attention facilitates exploration, which affects language development (see sections on 'Social interaction' and 'Embodiment' below), and that shifting attention towards changes in speech sounds (measured using ERP) also contributes to language development.

Attending to and integrating multiple sources of information. However, for optimal learning, not only must an infant orient to a speaking face, they must also look at the relevant parts of the face (e.g. the eyes [for gaze-following] or mouth [for disambiguating speech sounds]) and integrate visual and auditory information. For example, watching lip movements influences auditory (speech) perception (Alsius, Navarra, Campbell \& Soto-Faraco, 2005; Burnham \& Dodd, 2004; Kushnerenko, Teinonen, Volein \& Csibra, 2008; McGurk \& MacDonald, I976; Rosenblum, Schmuckler \& Johnson, r 997) and facilitates word learning (Teinonen, Aslin, Alku \& Csibra, 2008). Visual cues may be particularly useful for speech perception under noisy conditions (Sumby \& Pollack, I 954).

Could language delay in children with neurodevelopmental disorders partly result from a deficit in integrating auditory and visual information? To find out, we used an eye-tracker to measure auditory-visual (AV) speech integration in ninety-five infants/toddlers with Down syndrome, fragile $\mathrm{X}$ syndrome, or Williams syndrome, whom we matched on either chronological or mental age to twenty-five TD I5-month-old controls (D. D'Souza, D'Souza, Johnson \& Karmiloff-Smith, 2016). In this within-subjects design, the participants were presented with two faces. In one condition (Mismatch), the participants heard /ga/ while one face silently mouthed 'ga' (congruent) and the other face silently mouthed 'ba' (incongruent). The other condition (Fusion) was identical in all respects except the participants were presented with the sound /ba/ rather than /ga/. 
We predicted that TD infants would discriminate between the congruent and incongruent faces in the Mismatch condition with their looking behaviour, because when participants hear /ga/ and see 'ba', they perceive a mismatch - a combinatorial percept such as /bga/. We also predicted that TD infants would not visually discriminate between the congruent and incongruent faces in the Fusion condition, because the sound /ba/ and sight 'ga' fuses into the syllabic percept/da/ (the McGurk EFfect; McGurk \& MacDonald, I976), and participants with strong AV speech integration skills would demonstrate a McGurk effect and therefore not discriminate between the faces because there is nothing to distinguish one syllabic percept $(/ \mathrm{da} /)$ from the other $(/ \mathrm{ba} /)$. The TD controls showed the expected outcome. However, we found no evidence of $\mathrm{AV}$ speech integration in either the chronological- or mental-age-matched atypically developing groups (D. D'Souza, D'Souza, Johnson, \& Karmiloff-Smith, 2016). Moreover, whereas AV speech integration predicted receptive language ability in the TD controls, it did not in any of the atypically developing groups (D. D'Souza, D'Souza, Johnson, \& Karmiloff-Smith, 2016).

Why would AV speech integration not predict language ability in the neurodevelopmental disorders? We explored the possibility that the atypically developing children were fixating on the wrong parts of the face. We found that, when presented with a speaking face that mouthed a different syllable from the one they could hear, the TD infants $(N=25)$ with a relatively large vocabulary made more fixations to the mouth than eyes, while the toddlers with FXS $(N=$ I 4$)$ or WS $(N=25)$ and a relatively large vocabulary focused more on the eyes than mouth (D. D'Souza, D'Souza, Johnson \& Karmiloff-Smith, 20 I 5; see D. D'Souza, Cole, et al., 20 I 5, for more evidence that toddlers with WS process faces atypically). In DS $(N=2 \mathrm{I})$, by contrast, fixations to the speaker's overall face (rather than to the mouth or eyes) predicted vocabulary size (D. D'Souza, D'Souza et al., 20 I 5). This surprising result warrants further investigation. However, it suggests that children with these neurodevelopmental disorders are not using visual speech cues to bootstrap their acquisition of language in the same way as TD infants.

BEYOND COGNITION: OTHER DEVELOPMENTAL CONSTRAINTS ON LANGUAGE ACQUISITION

As shown above, under tightly controlled experimental conditions infants demonstrate an ability to assimilate information in ways that facilitate word learning. However, it is possible that they learn words in very different ways outside the laboratory. This is because different affordances may result in different adaptive behaviours, with some behaviours more optimal in the unfamiliar, tightly constrained, simplified environment of the laboratory, and others more optimal in the familiar but complex and 
dynamic environment of the home. What constrains language development outside the laboratory? In the following sections, we review evidence that language acquisition is constrained (among other things) by (i) social interaction and (ii) the infant's physical body.

\section{Social interaction}

Understanding language within complex natural environments may require different skills than the ones that are identified in intramural studies. There is some evidence to suggest that extracting linguistic structure from the environment requires social interaction: Nine-month-old American infants experienced twelve sessions of an unfamiliar language (Mandarin) through either live interaction with a Mandarin speaker or identical linguistic information from the same speaker but delivered via a television or audiotape (Kuhl, Tsao \& Liu, 2003). The American infants exposed to Mandarin in the live interaction condition could discriminate Mandarin phonemes similarly to age-matched Chinese Mandarin monolinguals. This shows that 9-month-olds can learn and/or retain their early ability to better discriminate non-native contrasts. However, the American infants exposed to Mandarin in the television and audiotape conditions failed to better discriminate between Mandarin phonemes than a group of age-matched American controls who had been exposed only to English.

Kuhl et al.'s (2003) data suggest that social interaction is important for language learning (even if it is unnecessary for simpler statistical learning tasks presented in experimental situations; e.g. Saffran et al., i 996). There are parallels of this in the non-human animal literature. For example, the young male zebra finch needs to see or physically interact with a 'tutor' bird to learn song (Adret, 2004; Eales, I989). Moreover, the song crystalizes during a sensitive period of early life, but a recent study found that this sensitive period could be extended through social interaction (Derégnaucourt, Poirier, Van der Kant, Van der Linden \& Gahr, 2013). In the study, after learning a song, young male zebra finches were moved to a common aviary where they could freely interact with other males. Zebra finches that had poorly imitated their song model during the sensitive period were more likely to change their song than zebra finches that had imitated their song model well. This highlights the importance of live social interaction on song learning in zebra finches. But what mechanisms underpin 'social learning' in the human infant? The zebra finch offers a clue. Preliminary data suggest that it imitates song better when its tutor is facing it (Ljubičić, Bruno \& Tchernichovski, 20I6). Perhaps an attentive tutor increases attention and arousal in the learner, enhancing its ability to learn and memorize information. Indeed, Yu and Smith (2016) found that human infants extend their sustained attention to an object when a parent 
attends to the same object. Kuhl (2007) suggests that social learning may facilitate language acquisition by increasing attention/arousal and/or providing additional sources of information (e.g. eye-contact, confirmatory glances from the instructor). ${ }^{7}$

Another example of how social interaction constrains language development comes from Karmiloff-Smith, Aschersleben, de Schonen, Elsabbagh, Hohenberger, and Serres (2010). In this study, 6-month-old infants were tested on their ability to process speech, faces, and actions/events. They were also observed and videotaped for 3 minutes as they played with their mothers, and the quality of each mother-infant dyadic interaction was rated. The infants were tested again at io months. At the group level, the infants displayed all of the expected effects found in previous research (e.g. the infants could discriminate both native and non-native contrasts at 6 months, but only native contrasts at io months). However, when Karmiloff-Smith and colleagues divided their data according to the motherchild interaction ratings, they found that the 6-month-old infants of highly sensitive (vs. controlling or unresponsive) mothers seemed to show earlier specialization for the sounds of their native language (i.e. they failed to significantly discriminate between the non-native contrasts). One might expect that interactions high on sensitivity would foster child development across cognitive domains generally. However, this was not the case. The infants from dyads highly rated for their sensitivity were in advance of their peers in speech processing at 6 months and in processing physical events at Io months, but were actually worse at processing human goal-directed actions than infants who were judged to be compliant and who also had moderately controlling mothers. Karmiloff-Smith et al. (2010) suggested that by imposing their own choice of toy on their infants and changing the toys without showing sensitivity to the infants' current focus of attention, the controlling mothers forced their compliant infants to frequently process their mothers' goals rather than their own goals, leading to an advantage in understanding others' goal-directed actions. Karmiloff-Smith et al., also suggested that, while sensitive mothers provide their infants with appropriate level linguistic input, controlling mothers speak less and are less likely to take into account the progressively changing nature of their child's vocalizations, leading to the differences in language development between the two groups of infants. And whereas sensitive mothers leave their infants sufficient time to fully explore (and learn about) the properties of objects, controlling mothers are more likely to interrupt their infants' exploration of

7 Kuhl (2007) also suggests that social learning may facilitate language acquisition by activating brain areas (e.g., 'mirror neurons' in Broca's area; Kilner, Neal, Weiskopf, Friston, \& Frith, 2009) that couple speech perception and action (Meister, Wilson, Deblieck, Wu, \& Iacoboni, 2007). However, this would not by itself explain why infants learn better from watching live instructors than instructors on television. 


$$
\text { D'SOUZA ET } A L \text {. }
$$

objects and offer them a succession of new toys, leading to differences in their infants' ability to process physical events (Karmiloff-Smith et al., 2010). Of course, these hypotheses need to be empirically tested, and we do not actually know whether the children were compliant (passive) because their mothers were moderately controlling, or whether the mothers displayed controlling behaviours because their children were compliant, or whether there is a different explanation. Nevertheless, the data indicate that differences in dyadic interaction are associated with differences in language development.

Motivated by the observations of Karmiloff-Smith et al. (2010), we measured various aspects of dyadic interaction in parent-infant dyads with Down syndrome or Williams syndrome. The first phase of our investigation found that, relative to eight chronological-age-matched TD dyads, sixteen dyads with DS or WS infants are lower in mutuality and engagement, parent responses are more controlling (directive) and less sensitive, and infants are less attentive to their parents and show less joint activity (Soukup-Ascençao, D'Souza, D'Souza \& Karmiloff-Smith, 2016). However, because parents are not necessarily intrinsically directive or sensitive, but adapt to their child's cognitive and linguistic characteristics (Hodapp, 2004), the second phase of our study will compare the DS/WS data with data from mental age (MA) matched TD infants and their parents. Because both syndromes present with uneven cognitive and social profiles (Karmiloff-Smith, Broadbent, et al., 2012; Moore, Oates, Hobson \& Goodwin, 2002), it is reasonable to expect that these atypicalities will yield different parental responses within the dyad in comparison to the parents of TD MA-matched infants (Hodapp, 2004). However, atypical parenting styles are not necessarily detrimental to infants with neurodevelopmental disorders; they could reflect adaptive processes and in fact facilitate language development. For example, it is possible that atypically developing infants may be more passive and thus require (and benefit from) more direction from their caregivers than typically developing infants. Therefore, in our future research, we are planning to link our parent-infant interaction measures with measures such as spontaneous exploration, visual attention, AV speech integration, and vocabulary size, to better understand how these complex social interactions constrain language development. ${ }^{8}$

\section{Embodiment}

Most studies on early language development (including many of those reviewed above) assume that the infant has the near-impossible task of

\footnotetext{
${ }^{8}$ We are planning to collect these (and other measures) from a longitudinal sample of thirtyfive children with Williams syndrome: <https://www.researchgate.net/project/Earlyprocesses-that-impact-later-development-in-Williams-syndrome>.
}

6 I 2 
having to extract structure by flexibly selecting and attending to things in relatively unconstrained, dynamically complex, cluttered, multimodal contexts. Attentively orienting to, disengaging from, shifting between, and engaging with various spinning toys, unpredictable sounds, eyes, mouths, and pointing behaviours, etc., can be challenging for infants (Kannass, Oakes \& Shaddy, 2006; Lansink, Mintz \& Richards, 2000; Ruff, Capozzoli \& Weissberg, I 998; Ruff \& Lawson, I 990), but the learning space may not be as unconstrained as many researchers assume. Learning is partly constrained by the environment, such as when the fetus hears its mother's voice but low-pass filtered through amniotic fluid, accentuating the rhythmic structure of speech (Smith, Gerhardt, Griffiths, Huang \& Abrams, 2003). But also, the learner's body constrains access to moment-to-moment sensory information, and in this way guides learning. For example, the neonate's short eyesight may restrict visual exploration to only the most salient features of an object; the infant's short arms may restrict exploration to only one object at a time; the toddler's short legs may restrict exploration to only part of a scene.

Furthermore, whereas researchers have focused on finding cognitive solutions to word learning problems such as referential ambiguity in early object naming (e.g. Xu \& Tenenbaum, 2007), Pereira, Smith, and Yu (2014) found that the occurrence of such ambiguous events might be limited by the sensorimotor constraints that underpin real-time free-flowing interactions. Specifically, they used a head-mounted camera to record gaze data from toddlers as they played with novel objects, and as the parent spontaneously named them. The toddlers were later tested to ascertain whether they had learned the names of the objects. This enabled the researchers to identify the properties of visually optimal moments for toddlers to learn the labels of objects: the toddlers learned best when the named object was visually larger and more centred than other objects, and when that visual advantage was sustained for several seconds before and after the naming event. This suggests that learning is constrained by the sensory properties of naming moments. That is, from an adult-centric perspective, the number of possible meanings that a novel word in a novel scene may have is so great that it provides the infant with an almost insurmountable problem of referential ambiguity, but research reflecting the child's perspective demonstrates that, during word learning, large numbers of objects are not typically in view, and that factors like the infant's physical abilities or size of visual field constrain the problem space (Samuelson \& McMurray, 20I6). In other words, cluttered visual scenes may provide the problem of referential ambiguity, but solutions that posit language-specific biases (e.g. Lidz, Waxman \& Freedman, 2003), strategies that deductively or statistically narrow down the set of possible word meanings (e.g. Golinkoff \& Hirsh-Pasek, 2006; Golinkoff, Mervis \& 


$$
\text { D’SOUZA } E T A L \text {. }
$$

Hirsh-Pasek, I 994; Xu \& Tenenbaum, 2007), and/or social skills such as inferring others' referential intent (e.g. Woodward \& Markman, I998), may be viable but are unnecessary; the active child creates moments of minimal visual ambiguity (by bringing objects close to their face with their short arms; Smith, Yu \& Pereira, 20 I ; Yu, Smith, Shen, Pereira \& Smith, 2009), rendering the cognitive problem obsolete. 9

The flipside of Pereira et al.'s (2014) findings is that they also point to visual LIMITS on object name learning, which highlights the need for infants to develop abilities that will enable them to learn in more challenging environments. Changes in the ability to use one's body (e.g. changes in posture, locomotion, object manipulation) help infants with this. That is, they enable the infant to explore and experience the world in new ways (Iverson, 2010). For example, children who can more easily pick up toys (because they are wearing 'sticky mittens') are more likely to explore different toys (Needham, Barrett \& Peterman, 2002; cf. Williams, Corbetta \& Guan, 2015), and the provision of toys for exploration is a significant predictor of language development (Elardo, Bradley \& Caldwell, I 977). And by learning to walk, an infant can bring a distant object of interest to an adult who can subsequently label it (Karasik, Tamis-LeMonda \& Adolph, 20I I). Indeed, in a longitudinal study of forty-four TD infants, Walle and Campos (2014) found that acquisition of walking predicts vocabulary size (both receptive and expressive), and that vocabulary size (receptive, expressive) significantly increases as a function of walking experience, irrespective of chronological age. But not only do motor changes help the child to sample more of its environment (and differently), they also require and develop cognitive problem solving skills (Adolph, 2005). Moreover, they 'prepare' the child for talking and listening. For example, by sitting up without assistance, an infant can breathe more efficiently, maintain subglottal pressure, and generate longer utterances in one breath (Iverson, 2010). By bringing objects to an adult, the infant may increase the number, and extend periods, of social interactions, which provides opportunities to learn important social behaviours such as turn-taking (Karasik et al., 20 I ; Walle \& Campos, 20I4). In a second observational study of forty-four parent-infant dyads during a ro-minute free-play session (when parents later reported that they did not remember they were being filmed), Walle and Campos (2014) found that the more active (walking or crawling) infants had larger receptive vocabulary sizes. They also found that, irrespective of chronological age, various factors in the social environment predicted

\footnotetext{
9 Other factors that constrain the problem space include biases such as novelty preference (the child is drawn to the most novel object in a context; Samuelson, Kucker, \& Spencer, 20I7; Samuelson \& Smith, I 998) and social interaction (caregivers often label whatever the child is attending to; Tomasello \& Todd, r 983 ).
}

\section{I 4}


vocabulary size - in walking, but not crawling, infants. Specifically, walking infants who received more language input from the parent had larger receptive and expressive vocabularies. Walking infants who spent more time at a 'medium' distance from the parent (nearby but out of the parent's physical reach) had larger expressive vocabularies, perhaps because a medium distance encourages distal communication. And walking infants whose parents moved around less frequently had larger receptive and expressive vocabularies, perhaps reflecting better distal dyadic communication and less need for physical intervention from the parent.

If individual differences in motor development constrain language acquisition in TD children, they have arguably an even greater effect on language development in atypically developing infants with genetic vulnerabilities. Motor difficulties are present early in development across various neurodevelopmental disorders. For example, infants with DS experience hypotonia, joint laxity, and hypermobility (Ulrich \& Ulrich, I993). And various motor skills, including walking, are delayed in DS. While the average age of walking in TD children is $\mathrm{I} 3$ months and the age range is from 9 to $\mathrm{I} 7$ months, most children with DS only learn to walk between 2 and 3 years of age - with some children unable to walk at 4 years of age (Palisano et al., 200I). Even when children with DS learn a new motor skill, they tend to practise it less. For example, de Campos, da Costa, Savelsbergh, and Rocha (2013) found that, even after onset of reaching, infants with DS $(N=9)$ produce significantly fewer spontaneous reaches than TD controls $\left(N={ }_{1} 6\right)$. This may constrain their exploration of objects (and require more input from the caregiver), which could further contribute to language delay. However, interventions can hasten the late onset of motor skills. For example, infants with DS who underwent a home-based stepping training intervention achieved independent walking I о I days earlier (on average) than infants with DS who had not taken part in the intervention (Ulrich, Ulrich, Angulo-Kinzler \& Yun, 200I). We hypothesize that, because the motor domain does not exist in isolation (see above), early intervention in the motor domain may also have cascading effects on connected, interdependent domains, such as language.

\section{IMPLICATIONS, CHALLENGES, AND NEW DIRECTIONS: EMBRACING COMPLEXITY}

Several decades of infant research demonstrate that word learning is constrained by multiple factors (some of which were discussed abovero) that range from the amount and quality of linguistic input they receive to

Io Social interaction and motor activity constrain sampling, learning, and attentional processes during the waking day. But infants spend most of their time asleep 


$$
\text { D'SOUZA ET } A L \text {. }
$$

the length of their arms. It is important to note, however, that arguably all of the developmental processes, domains, and levels of description discussed in this paper are INTERCONNECTED. For example, habituation processes are likely to constrain language development through learning and memory, but also they are yoked to attentional processes that trigger novelty-seeking behaviour, and constrain exploratory behaviour (more time spent consolidating knowledge is likely to result in less time exploring). Many of the developmental processes, domains, and levels of description are also INTERDEPENDENT. For example, Down syndrome affects how an infant develops partly through the complex interactions the infant has with its parent; parenting constrains the infant's development, but the infant's development affects parenting. And because interactions between diverse, interdependent units give rise to non-linear dynamics, in order to understand how the system develops we cannot study the components of the system in isolation. ${ }^{\text {I }}$ Understanding how infants acquire language therefore necessitates multidisciplinary research across multiple interdependent domains (e.g. sampling, learning, attention), modalities (e.g. haptic, auditory, visual), and levels of description (from genes to social context) over developmental time. ${ }^{\mathrm{I} 2}$

Furthermore, to study how complex systems adapt to their environments, it is important to study them in their environment. Moreover, because language development is a probabilistic process, there are likely to be multiple ways to an adaptive fit. Arguably, researchers should therefore abandon attempts to find ONE developmental pathway to language acquisition and instead identify co-varying factors that significantly constrain development. This is crucial if we want to understand how

(Iglowstein, Jenni, Molinari, \& Largo, 2003). Do variations in sleep patterns impact language development? In a study of sixty infants/toddlers with DS, FXS, or WS, and sixty age-matched TD controls, we found that sleep variables (e.g., sleep duration) are associated with vocabulary size in typical and atypical development-especially in WS (D. D'Souza, D'Souza, Horvath, \& Karmiloff-Smith, 2016). Sleep development and its impact on language in neurodevelopmental disorders will be an important area of focus in the future.

I As a rough rule of thumb, the interaction of INDEPENDENT units gives rise to a normal distribution and linear dynamics (e.g., if vocabulary size increases as a function of maturational age), while the interaction of INTERDEPENDENT units gives rise to a power distribution and non-linear dynamics (e.g., if language development increases opportunities for social interaction, and social interaction facilities language development) (Miller \& Page, 2007).

I2 An example of this is the London Down Syndrome Consortium, which seeks to understand the link between Down syndrome and Alzheimer's disease, and comprises clinicians, developmental psychologists, psychiatrists, cellular scientists, human geneticists, and mouse geneticists. This example highlights one of the challenges of embracing complexity: because it involves large numbers of variables, multiple methods, and experts at different levels of description, it requires the coordination of large multidisciplinary collaborations and a shared theoretical perspective (H. D'Souza \& Karmiloff-Smith, 20I6). 
language development goes awry in infants with neurodevelopmental disorders.

How can we hope to understand language development if it requires an understanding of the multiple ways in which different but interdependent domains, modalities, and levels of description interact with each other over developmental time? Technological and methodological innovations will aid the process. For example, new or improving technologies such as head-mounted eye-trackers for infants will enable more naturalistic studies. And the increasing size and complexity of datasets collected during studies that, e.g. involve moment-by-moment gaze data from eye-trackers mounted on the heads of infants as they explore their home environment, are being paralleled by increases in computational power and the development of tools that can store, catalogue, and analyze massive datasets (see Arzi et al., 2014, for discussion). These tools may also help researchers from around the world to share and collate data such as the speech corpus contained within the Child Language Data Exchange System (CHILDES), a central repository for language acquisition data, or the digital data library (Databrary) which facilitates the sharing and repurposing of video data. Creating a similar platform for data gathered from infants with a neurodevelopmental disorder would enable us to repurpose data and gain more insight into how learning happens moment-by-moment in these often difficult-to-study populations.

Theoretical and conceptual advancements are also important because they guide what scientists decide to study and how they study it (H. D'Souza \& Karmiloff-Smith, 2016). Furthermore, they lead to better explanatory and predictive models of language development, and can shape social practice, education, and intervention. Take intervention, for example. To tackle language delay in children with neurodevelopmental disorders, paediatricians often target the purported malfunctioning 'language module' with specific outcomes in mind, such as teaching the child to produce a set of words. However, the developmental studies discussed in this paper suggest that, because language emerges gradually from the interaction of many diverse interdependent units over time, any delay may be the result of cascading effects of early impairments in non-linguistic domains (e.g. in selective attention). In this case, successful intervention would require targeting mechanisms and domains that are not necessarily directly related to the language domain and which could be on different levels of description (e.g. emotional dysregulation). Moreover, because the child is a complex adaptive system, timely intervention is likely to be critical (D. D’Souza \& Karmiloff-Smith, 20I6). ${ }^{\text {I3 }}$ That is, teaching a child

${ }^{13}$ The developmental trajectory of a complex adaptive system is largely dependent on its first few 'steps' (Path Dependence; Miller \& Page, 2007). 


$$
\text { D’SOUZA } E T A L \text {. }
$$

to learn words may be particularly challenging if the child has not, for example, developed adequate oro-motor abilities. Furthermore, because the child is a complex adaptive system, rather than attempt to restructure one particular domain such as language (e.g. by providing the child with more language lessons), it would be better to focus on creating an environment for optimal learning. This may involve various strategies such as keeping the child on the edge of the boundary between consolidating knowledge (e.g. allowing the child time to process a stimulus) and searching for new knowledge (e.g. providing the child with novel stimuli). In other words, new theoretical perspectives view the child as a complex adaptive system and suggest that it would be best to gain an understanding of, and build interventions around, the interdependency of various factors.

\section{CONCLUSION}

We have reviewed evidence for the existence of several diverse, interacting, interdependent (linguistic and non-linguistic) constraints on language development. This evidence suggests that many aspects of language are constructed piecemeal via the complex and dynamic interactions of parts within the infant as well as between the infant and its social and physical environments. Language delay is at least in part due to variations in these constraints. Future research on language development should therefore not only focus on single cues (e.g. prosodic patterns, stress patterns, the social context of the interaction) or on single domains (e.g. attention, learning, social interaction); it should integrate data from different domains and levels of description. These cues/domains are neither individually sufficient nor independent of each other, but rather they are used in combination to constrain the learning space and allow probabilistic knowledge to emerge. Future studies should therefore investigate how infants integrate multiple sources of information in naturalistic contexts and across developmental time. This may lead to a better understanding of language development and, critically, lead to more effective interventions for cases when language develops atypically.

\section{REFERENCES}

Adolph, K. E. (2005). Learning to learn in the development of action. In John J. Rieser, Jeffrey J. Lockman \& Charles A. Nelson (eds), Action as an organizer of perception and cognition during learning and development: Minnesota Symposium on Child Development, Vol. 33 (pp. 9I-I 22). Online: <https://psych.nyu.edu/adolph/publications/2005Adolph\% $20 \mathrm{~K} \% 20 \mathrm{E}-$ Learning $\% 20$ to $\% 2$ olearn $\% 20$ in $\% 20$ the $\% 2$ odevelopment $\% 200 \mathrm{f} \% 20$ action.pdf $>$.

Adret, P. (2004). Vocal imitation in blindfolded zebra finches (Taeniopygia guttata) is facilitated in the presence of a non-singing conspecific female. Fournal of Ethology 22(I), 29-35. 
Alsius, A., Navarra, J., Campbell, R. \& Soto-Faraco, S. (2005). Audiovisual integration of speech falters under high attention demands. Current Biology 15(9), 839-43.

Arzi, A., Banerjee, S., Cox, J. C., D’Souza, D., De Brigard, F., Doll, B. B. ... Woo, S. (20 I4). The significance of cognitive neuroscience: findings, applications, and challenges. In $\mathrm{M}$. S. Gazzaniga \& G. R. Mangun (eds), The cognitive neurosciences, 5th ed. (pp. I07I-1078). Cambridge, MA: MIT Press.

Atkinson, J., Hood, B., Braddick, O. \& Wattam-Bell, J. (i988). Infant's control of fixation shifts with single and competing targets: mechanisms for shifting attention. Perception I 7, $367-8$.

Bates, E., Benigni, L., Bretherton, I., Camaioni, L. \& Volterra, V. (1979). The emergence of symbols: cognition and communication in infancy. New York: Academic Press.

Bates, E. \& Elman, J. L. (I993). Connectionism and the study of change. In Mark Johnson (ed.), Brain development and cognition: a reader (pp. 623-642). Oxford: Blackwell.

Benasich, A. A., Choudhury, N. A., Realpe-Bonilla, T. \& Roesler, C. P. (2014). Plasticity in developing brain: active auditory exposure impacts prelinguistic acoustic mapping. Fournal of Neuroscience 34(40), I 3349-63.

Bertoncini, J., Bijeljac-Babic, R., Blumstein, S. E. \& Mehler, J. (1987). Discrimination in neonates of very short CVs. Fournal of the Acoustical Society of America 82(I), 3 I-7.

Blanpied, T. A. \& Ehlers, M. D. (2004). Microanatomy of dendritic spines: emerging principles of synaptic pathology in psychiatric and neurological disease. Biological Psychiatry 55(12), I I 2 I-7.

Blumberg, M. S. (2016). Development evolving: the origins and meanings of instinct. WIREs Cognitive Science. Doi: Io. I002/wcs. I 37 I.

Bornstein, M. H. \& Sigman, M. D. ( I 986). Continuity in mental development from infancy. Child Development 57, $25 \mathrm{I}-74$.

Bosch, L. \& Ramon-Casas, M. (20I I). Variability in vowel production by bilingual speakers: Can input properties hinder the early stabilization of contrastive categories? Fournal of Phonetics 39(4), 514-26.

Bosch, L. \& Sebastián-Gallés, N. (2003). Simultaneous bilingualism and the perception of a language-specific vowel contrast in the first year of life. Language and Speech 46(2/3), 2 I 7-43.

Bourgeron, T. (2009). A synaptic trek to autism. Current Opinion in Neurobiology 19(2), 23 I-4.

Brauer, J. \& Friederici, A. D. (2007). Functional neural networks of semantic and syntactic processes in the developing brain. Fournal of Cognitive Neuroscience r9(10), r609-23.

Brooks, R. \& Meltzoff, A. N. (2005). The development of gaze following and its relation to language. Developmental Science 8(6), 535-43.

Brown, J. H., Johnson, M. H., Paterson, S. J., Gilmore, R., Longhi, E. \& Karmiloff-Smith, A. (2003). Spatial representation and attention in toddlers with Williams syndrome and Down syndrome. Neuropsychologia 4r(8), ı $037-46$.

Brown, T. T., Petersen, S. E. \& Schlaggar, B. L. (2006). Does human functional brain organization shift from diffuse to focal with development? Developmental Science 9( I), 9-I I .

Burnham, D. \& Dodd, B. (2004). Auditory-visual speech integration by prelinguistic infants: perception of an emergent consonant in the McGurk effect. Developmental Psychobiology 45 (4), 204-20.

Butterworth, G. (1998). 'What is special about pointing in babies?' In S. Francesca \& Butterworth, G. (eds). The development of sensory, motor, and cognitive capacities in early infancy, I 7 I-90. Hove: Psychology Press.

Buzsaki, G. (2006). Rhythms of the brain. Oxford: Oxford University Press.

Byers-Heinlein, K. (2013). Parental language mixing: its measurement and the relation of mixed input to young bilingual children's vocabulary size. Bilingualism: Language and Cognition r6(I), 32-48.

Byers-Heinlein, K. \& Fennell, C. T. (20I4). Perceptual narrowing in the context of increased variation: insights from bilingual infants. Developmental Psychobiology 65(2), 274-91 .

Cardoso-Martins, C. \& Mervis, C. (1985). Maternal speech to prelinguistic children with Down syndrome. American Fournal of Mental Deficiency 89, 45 I-8. 
Cashon, C. H., Ha, O. R., Estes, K. G., Saffran, J. R. \& Mervis, C. B. (2016). Infants with Williams syndrome detect statistical regularities in continuous speech. Cognition I54, I65-8.

Chailangkarn, T., Trujillo, C. A., Freitas, B. C., Hrvoj-Mihic, B., Herai, R. H., Yu, D. X., ... Muotri, A. R. (2016). A human neurodevelopmental model for Williams syndrome. Nature 536, 338-43.

Chomsky, N. (I959). Review of Skinner's Verbal Behavior. Language 35, 26-58.

Chomsky, N. (r 975). Reflections on language. New York: Pantheon Books.

Chomsky, N. (I99I). Linguistics and cognitive science: problems and mysteries. In A. Kasher (ed.), The Chomskyan turn (pp. 26-53). Cambridge, MA: Blackwell.

Choudhury, N. \& Benasich, A. A. (20I I). Maturation of auditory evoked potentials from 6 to 48 months: prediction to 3 and 4 year language and cognitive abilities. Clinical Neurophysiology 122(2), 320-38.

Clancy, B., Darlington, R. B. \& Finlay, B. L. (2000). The course of human events: predicting the timing of primate neural development. Developmental Science 3(I), 57-66.

Coffey-Corina, S., Padden, D. \& Kuhl, P. K. (2008). ERPs to words correlate with behavioral measures in children with Autism Spectrum Disorder. In Proceedings-European Conference on Noise Control 5I6I-6. Online: <https://iths.pure.elsevier.com/en/ publications/erps-to-words-correlate-with-behavioral-measures-in-children-with>.

Colombo, J. \& Mitchell, D. W. (I 990). Individual differences in early visual attention: fixation time and information processing. In J. Colombo \& J. W. Fagen (eds), Individual differences in infancy: reliability, stability, prediction, I 93-227. Hillsdale, NJ: Erlbaum.

Colombo, J., Shaddy, D. J., Richman, W. A., Maikranz, J. M. \& Blaga, O. M. (2004). The developmental course of habituation in infancy and preschool outcome. Infancy 5 ( I ) , I-38.

de Campos, A. C., da Costa, C. S. N., Savelsbergh, G. J. \& Rocha, N. A. C. F. (20I3). Infants with Down syndrome and their interactions with objects: development of exploratory actions after reaching onset. Research in Developmental Disabilities 34(6), r 906-i 6.

Dehaene-Lambertz, G. \& Spelke, E. S. (20I5). The infancy of the human brain. Neuron 88 (I), 93-ro9.

Derégnaucourt, S., Poirier, C., Van der Kant, A., Van der Linden, A. \& Gahr, M. (2013). Comparisons of different methods to train a young zebra finch (Taeniopygia guttata) to learn a song. Fournal of Physiology-Paris ro7(3), 2 10-8.

Dinstein, I., Heeger, D. J., Lorenzi, L., Minshew, N. J., Malach, R. \& Behrmann, M. (2012). Unreliable evoked responses in autism. Neuron 75(6), $98 \mathrm{I}-9 \mathrm{I}$.

D'Souza, D. (2014). Are early cognitive and neurophysiological markers of autism syndromespecific? A cross-syndrome comparison. Unpublished doctoral thesis, University of London, London, UK.

D’Souza, D., Cole, V., Farran, E. K., Brown, J. H., Humphreys, K., Howard, J., Rodic, M., Dekker, T. M., D'Souza, H. \& Karmiloff-Smith, A. (20 I5). Face processing in Williams syndrome is already atypical in infancy. Frontiers in Psychology 6, 760.

D’Souza, D. \& D’Souza, H. (2016). Bilingual language control mechanisms in anterior cingulate cortex and dorsolateral prefrontal cortex: a developmental perspective. Fournal of Neuroscience 36(20), 5434-6.

D'Souza, D., D'Souza, H., Horvath, K. \& Karmiloff-Smith, A. (2016). Sleep and language development: insights from a cross-syndrome study. Poster presented at the XX Biennial International Conference on Infant Studies, International Society on Infant Studies, New Orleans, USA.

D’Souza, D., D’Souza, H., Johnson, M. H. \& Karmiloff-Smith, A. (2015). Concurrent relations between face scanning and language: a cross-syndrome infant study. PloS One ro(io), eor 393 I 9.

D’Souza, D., D’Souza, D., Johnson, M. H. \& Karmiloff-Smith, A. (2016). Audio-visual speech perception in infants and toddlers with Down syndrome, fragile $\mathrm{X}$ syndrome, and Williams syndrome. Infant Behavior and Development 44, 249-62. 
D'Souza, D. \& Karmiloff-Smith, A. (20II). When modularization fails to occur: a developmental perspective. Cognitive Neuropsychology 28(3/4), 276-87.

D'Souza, D. \& Karmiloff-Smith, A. (2016). Why a developmental perspective is critical for understanding human cognition. Behavioral and Brain Sciences 39, eI22. doi:Io. Ior7/ SoI $40525 \mathrm{XI}_{5}$ O0 I 569 .

D’Souza, D., Kyjonková, H., Johnson, M. H., Gliga, T., Kushnerenko, E., Scerif, G. \& BASIS Team (2013). Are early neurophysiological markers of ASD syndrome-specific? Preliminary results from a cross-syndrome study. In Annual Meeting of the International Society for Autism Research, IMFAR.

D’Souza, H., Cowie, D., Karmiloff-Smith, A. \& Bremner, A. J. (2016). Specialization of the motor system in infancy: from broad tuning to selectively specialized purposeful actions. Developmental Science. [Early View.] doi: I o. I I I I/desc. I 2409.

D'Souza, H. \& Karmiloff-Smith, A. (2016). Neurodevelopmental disorders. WIREs Cognitive Science. Doi: 10. 1002/wcs. I 398.

Eales, L. (1989). The influences of visual and vocal interaction on song learning in zebra finches. Animal Behavior 37, 507-8.

Echols, C. H., Crowhurst, M. J. \& Childers, J. B. (I 997). The perception of rhythmic units in speech by infants and adults. Fournal of Memory and Language 36(2), 202-25.

Edgin, J. O. (2013). Cognition in Down syndrome: a developmental cognitive neuroscience perspective. WIREs Cognitive Science 4, 307-I 7.

Eimas, P. D., Siqueland, E. R., Jusczyk, P. \& Vigorito, J. (I97I). Speech perception in infants. Science I7I(3968), 303-6.

Elardo, R., Bradley, R. \& Caldwell, B. M. ( I 977). A longitudinal study of the relation of infants' home environments to language development at age three. Child Development 48(2), 595-603.

Elman, J. L. ( I 993). Learning and development in neural networks: the importance of starting small. Cognition 48( I), 7I-99.

Elman, J. L., Bates, E. A., Johnson, M. H., Karmiloff-Smith, A., Parisi, D. \& Plunkett, K. ( 1996). Rethinking innateness. Cambridge, MA: MIT Press.

Fiala, J. C., Spacek, J. \& Harris, K. M. (2002). Dendritic spine pathology: cause or consequence of neurological disorders? Brain Research Reviews 39(I), 29-54.

Frankenhuis, W. E. \& Panchanathan, K. (20 I Ia). Balancing sampling and specialization: an adaptationist model of incremental development. Proceedings of the Royal Society B: Biological Sciences 278, 3558-65.

Frankenhuis, W. E. \& Panchanathan, K. (20I Ib). Individual differences in developmental plasticity may result from stochastic sampling. Perspectives on Psychological Science 6(4), $336-47$.

Gandal, M. J., Edgar, J. C., Ehrlichman, R. S., Mehta, M., Roberts, T. P. \& Siegel, S. J. (2010). Validating $\gamma$ oscillations and delayed auditory responses as translational biomarkers of autism. Biological Psychiatry 68( 1 2), i I о०-6.

Gilman, S. R., Iossifov, I., Levy, D., Ronemus, M., Wigler, M. \& Vitkup, D. (20 I I). Rare de novo variants associated with autism implicate a large functional network of genes involved in formation and function of synapses. Neuron $\mathbf{7 0}(5), 898-907$.

Golinkoff, R. M. \& Hirsh-Pasek, K. (2006). Baby wordsmith from associationist to social sophisticate. Current Directions in Psychological Science r5(I), 30-3.

Golinkoff, R. M., Mervis, C. B. \& Hirsh-Pasek, K. (r 994). Early object labels: the case for a developmental lexical principles framework. Fournal of Child Language 2I(I), I 25-55.

Graf Estes, K., Evans, J. L., Alibali, M. W. \& Saffran, J. R. (2007). Can infants map meaning to newly segmented words? Statistical segmentation and word learning. Psychological Science $\mathbf{1 8}(3), 254-60$.

Greenough, W. T., Black, J. E. \& Wallace, C. S. (I987) Experience and brain development. Child Development 58, 539-59.

Guiraud, J. A., Kushnerenko, E., Tomalski, P., Davies, K., Ribeiro, H., Johnson, M. H. \& BASIS Team. (20I I). Differential habituation to repeated sounds in infants at high risk for autism. Neuroreport 22(I6), 845-9. 


$$
\text { D’SOUZA } E T A L \text {. }
$$

Hockema, S. A. \& Smith, L. B. (2009). Learning your language, outside-in and inside-out. Linguistics 47(2), 453-79.

Hodapp, R. M. (2004). Studying interactions, reactions and perceptions: Can genetic disorders serve as behavioural proxies? Fournal of Autism and Developmental Disorders 34 (I), 29-34.

Hoff, E., Welsh, S., Place, S. \& Ribot, K. M. (2014). Properties of dual language input that shape bilingual development and properties of environments that shape dual language input. In T. Grüter \& J. Paradis (eds), Input and experience in bilingual developmentVol. I3, I I9-40. Amsterdam: John Benjamins.

Hsu, H. J. \& Bishop, D. V. M. (2010). Grammatical difficulties in children with specific language impairment (SLI): Is learning deficient? Human Development 53, 264-77.

Iglowstein, I., Jenni, O. G., Molinari, L. \& Largo, R. H. (2003). Sleep duration from infancy to adolescence: reference values and generational trends. Pediatrics III(2), 302-7.

Irwin, S. A., Galvez, R. \& Greenough, W. T. (2000). Dendritic spine structural anomalies in fragile-X mental retardation syndrome. Cerebral Cortex 1о( (о), , го38-44.

Iverson, J. M. (2010). Developing language in a developing body: the relationship between motor development and language development. Fournal of Child Language 37(2), 229-6r.

Johnson, M. H. (20I I). Interactive specialization: A domain-general framework for human functional brain development? Developmental Cognitive Neuroscience I(I), 7-2 I.

Johnson, M. H., Jones, E. J. H. \& Gliga, T. (2015). Brain adaptation and alternative developmental trajectories. Development and Psychopathology 27(2), 425-42.

Jones, E. J., Gliga, T., Bedford, R., Charman, T. \& Johnson, M. H. (2014). Developmental pathways to autism: a review of prospective studies of infants at risk. Neuroscience and Biobehavioral Reviews 39, I-33.

Jusczyk, P. W., Houston, D. M. \& Newsome, M. (I999). The beginnings of word segmentation in English-learning infants. Cognitive Psychology 39, I 59-207.

Kannass, K. N., Oakes, L. M. \& Shaddy, D. J. (2006). A longitudinal investigation of the development of attention and distractibility. Fournal of Cognition and Development 7(3), $38 \mathrm{I}-409$.

Kanwisher, N. \& Wojciulik, E. (2000). Visual attention: insights from brain imaging. Nature Reviews Neuroscience $\mathbf{I}(2)$, 9 $\mathrm{I}-\mathrm{I} 00$.

Karasik, L. B., Tamis-LeMonda, C. S. \& Adolph, K. E. (201 I). Transition from crawling to walking and infants' actions with objects and people. Child Development 82(4), I I99-209.

Karmiloff-Smith, A. (1992). Beyond modularity: a developmental perspective on cognitive science. Cambridge, MA: MIT press.

Karmiloff-Smith, A., Aschersleben, G., de Schonen, S., Elsabbagh, M., Hohenberger, A. \& Serres, J. (20I0). Constraints on the timing of infant cognitive change: Domain-specific or domain-general? International Fournal of Developmental Science 4(I), 3 I-45.

Karmiloff-Smith, A., Broadbent, H., Farran, E. K., Longhi, E., D’Souza, D., Metcalfe, K., ... \& Sansbury, F. (2012). Social cognition in Williams syndrome: genotype/phenotype insights from partial deletion patients. Frontiers in Psychology 3, I68.

Karmiloff-Smith, A., D’Souza, D., Dekker, T. M., Van Herwegen, J., Xu, F., Rodic, M. \& Ansari, D. (2012). Genetic and environmental vulnerabilities in children with neurodevelopmental disorders. Proceedings of the National Academy of Sciences ro9 (Supplement 2), I 726I-65.

Kaufmann, W. E. \& Moser, H. W. (2000). Dendritic anomalies in disorders associated with mental retardation. Cerebral Cortex Iо(г), $98 \mathrm{I}-9 \mathrm{I}$.

Kavšek, M. (2004). Predicting later IQ from infant visual habituation and dishabituation: a meta-analysis. Fournal of Applied Developmental Psychology 25(3), 369-93.

Kilner, J. M., Neal, A., Weiskopf, N., Friston, K. J. \& Frith, C. D. (2009). Evidence of mirror neurons in human inferior frontal gyrus. Fournal of Neuroscience 29(32), Ior 53-59.

Kirkham, N. Z., Slemmer, J. A. \& Johnson, S. P. (2002). Visual statistical learning in infancy: evidence for a domain general learning mechanism. Cognition $83(2), \mathrm{B}_{35}-42$.

Kuhl, P. K. (2004). Early language acquisition: cracking the speech code. Nature Reviews Neuroscience 5(I I), $83 \mathrm{I}-43$. 
Kuhl, P. K. (2007). Is speech learning 'gated' by the social brain? Developmental Science ro(r), I IO-20.

Kuhl, P. K., Conboy, B. T., Coffey-Corina, S., Padden, D., Rivera-Gaxiola, M. \& Nelson, T. (2008). Phonetic learning as a pathway to language: new data and native language magnet theory expanded (NLM-e). Philosophical Transactions of the Royal Society of London B: Biological Sciences 363(I493), 979-Iо00.

Kuhl, P. K., Conboy, B. T., Padden, D., Nelson, T. \& Pruitt, J. (2005). Early speech perception and later language development: implications for the 'critical period'. Language Learning and Development $\mathbf{I}(3 / 4), 237-64$.

Kuhl, P. K., Stevens, E., Hayashi, A., Deguchi, T., Kiritani, S. \& Iverson, P. (2006). Infants show a facilitation effect for native language phonetic perception between 6 and 12 months. Developmental Science $9(2), \mathrm{F}_{\mathrm{I}} 3^{-2} \mathrm{I}$.

Kuhl, P. K., Tsao, F. M. \& Liu, H. M. (2003). Foreign-language experience in infancy: effects of short-term exposure and social interaction on phonetic learning. Proceedings of the National Academy of Sciences Ioo(I 5), 9096-го I.

Kushnerenko, E., Teinonen, T., Volein, A. \& Csibra, G. (2008). Electrophysiological evidence of illusory audiovisual speech percept in human infants. Proceedings of the National Academy of Sciences ro5(32), I I 442-45.

Laing, E., Butterworth, G., Ansari, D., Gsödl, M., Longhi, E., Panagiotaki, G., Paterson, S. \& Karmiloff-Smith, A. (2002). Atypical development of language and social communication in toddlers with Williams syndrome. Developmental Science 5(2), 233-46.

Lansink, J. M., Mintz, S. \& Richards, J. E. (2000). The distribution of infant attention during object examination. Developmental Science 3(2), I63-70.

Lany, J. \& Saffran, J. R. (2010). From statistics to meaning: infants' acquisition of lexical categories. Psychological Science 2I(2), 284-9I.

Levitin, D. J., Menon, V., Schmitt, J. E., Eliez, S., White, C. D., Glover, G. H., ... \& Reiss, A. L. (2003). Neural correlates of auditory perception in Williams syndrome: an fMRI study. Neuroimage $\mathbf{1 8}(\mathrm{I}), 74-82$.

Lidz, J., Waxman, S. \& Freedman, J. (2003). What infants know about syntax but couldn't have learned: experimental evidence for syntactic structure at I 8 months. Cognition 89(3), 295-303.

Lickliter, R. (2016). Developmental evolution. WIREs Cognitive Science. Doi:I0.1002/ wcs. I 422 .

Ljubičić, I., Bruno, J. H. \& Tchernichovski, O. (2016). Social influences on song learning. Current Opinion in Behavioral Sciences 7, IоI-7.

Lord, C., Rutter, M., Goode, S., Heemsbergen, J., Jordan, H., Mawhood, L. \& Schopler, E. (I989). Austism diagnostic observation schedule: a standardized observation of communicative and social behavior. Fournal of Autism and Developmental Disorders 19(2), I $85^{-2}$ I 2 .

Macchi Cassia, V., Bulf, H., Quadrelli, E. \& Proietti, V. (2014). Age-related face processing bias in infancy: evidence of perceptual narrowing for adult faces. Developmental Psychobiology 56(2), 238-48.

Mareschal, D., Johnson, M. H., Sirois, S., Spratling, M. W., Thomas, M. S. C. \& Westermann, G. (2007). Neuroconstructivism: how the brain constructs cognition (Vol. I). New York, NY: Oxford University Press.

Markram, H., Rinaldi, T. \& Markram, K. (2007). The intense world syndrome-an alternative hypothesis for autism. Frontiers in Neuroscience $\mathbf{I}, 6$.

Martin, C. D., Molnar, M. \& Carreiras, M. (20I6). The proactive bilingual brain: using interlocutor identity to generate predictions for language processing. Scientific Reports 6 (26I7I).

McCall, R. B. \& Carriger, M. S. (r993). A meta-analysis of infant habituation and recognition memory performance as predictors of later IQ. Child Development 64, 57-79.

McGurk, H. \& MacDonald, J. (I976). Hearing lips and seeing voices. Nature 264, 746-8.

Meister, I. G., Wilson, S. M., Deblieck, C., Wu, A. D. \& Iacoboni, M. (2007). The essential role of premotor cortex in speech perception. Current Biology I7(I9), I692-6. 


\section{D'SOUZA $E T A L$.}

Mervis, C. B. \& Bertrand, J. (1997). Developmental relations between cognition and language: evidence from Williams syndrome. In L. B. Adamson \& M. A. Romski MA (eds), Communication and language acquisition: discoveries from atypical development, 75-106. Baltimore, MD: Paul H. Brookes.

Miller, J. H. \& Page, S. E. (2007). Complex adaptive systems: an introduction to computational models of social life. Princeton, NJ: Princeton University Press.

Minagawa-Kawai, Y., Mori, K., Naoi, N. \& Kojima, S. (2007). Neural attunement processes in infants during the acquisition of a language-specific phonemic contrast. Fournal of Neuroscience 27(2), 3 I 5-2 I.

Moore, D. G., Oates, J. M., Hobson, R. P. \& Goodwin, J. (2002). Cognitive and social factors in the development of infants with Down syndrome. Down Syndrome Research and Practice 8(2), 43-52.

Morales, M., Mundy, P. \& Rojas, J. (1998). Following the direction of gaze and language development in 6-month-olds. Infant Behavior and Development 21(2), 373-7.

Morgan, J. L. \& Saffran, J. R. (I 995). Emerging integration of sequential and suprasegmental information in preverbal speech segmentation. Child Development 66(4), 91 I-36.

Mower, G. D., Caplan, C. J., Christen, W. G. \& Duffy, F. H. (I985). Dark rearing prolongs physiological but not anatomical plasticity of the cat visual cortex. Fournal of Comparative Neurology 235(4), 448-66.

Mundy, P. \& Gomes, A. (1998). Individual differences in joint attention skill development in the second year. Infant Behavior and Development 2I(3), 469-82.

Nazzi, T., Paterson, S. \& Karmiloff-Smith, A. (2003). Early word segmentation by infants and toddlers with Williams syndrome. Infancy 4(2), $25 \mathrm{I}-7 \mathrm{I}$.

Needham, A., Barrett, T. \& Peterman, K. (2002). A pick-me-up for infants' exploratory skills: early simulated experiences reaching for objects using 'sticky mittens' enhances young infants' object exploration skills. Infant Behavior and Development 25(3), 279-95.

Nimchinsky, E. A., Sabatini, B. L. \& Svoboda, K. (2002). Structure and function of dendritic spines. Annual Review of Physiology 64(I), 31 3-53.

Palisano, R. J., Walter, S. D., Russell, D. J., Rosenbaum, P. L., Gémus, M., Galuppi, B. E. \& Cunningham, L. (200I). Gross motor function of children with Down syndrome: creation of motor growth curves. Archives of Physical Medicine and Rehabilitation 82(4), 494-500.

Pascalis, O., de Haan, M. \& Nelson, C. A. (2002). Is face processing species-specific during the first year of life? Science 296, I $32 \mathrm{I}-3$.

Pascalis, O., Scott, L. S., Kelly, D. J., Shannon, R. W., Nicholson, E., Coleman, M. \& Nelson, C. A. (2005). Plasticity of face processing in infancy. Proceedings of the National Academy of Sciences of the United States of America Io2(14), 5297-300.

Pereira, A. F., Smith, L. B. \& Yu, C. (20I4). A bottom-up view of toddler word learning. Psychonomic Bulletin \& Review 2I(I), $178-85$.

Piaget, J. (1954). The construction of reality in the child. New York, NY: Basic Books.

$\mathrm{Pi}$ Casaus, G. (2015). The role of experience in perceptual reorganization: the case of bilingual infants. Unpublished doctoral thesis, Universitat Pompeu Fabra, Barcelona, Spain.

Pinker, S. ( 1 994). The language instinct. New York, NY: Morrow.

Power, J. D. \& Schlaggar, B. L. (2016). Neural plasticity across the lifespan. WIREs Cognitive Science. Doi: I0.1002/wdev.2 I6.

Rankin, C. H., Abrams, T., Barry, R. J., Bhatnagar, S., Clayton, D. F., Colombo, J., ... \& McSweeney, F. K. (2009). Habituation revisited: an updated and revised description of the behavioral characteristics of habituation. Neurobiology of Learning and Memory 92(2), I35-8.

Romberg, A. R. \& Saffran, J. R. (2010). Statistical learning and language acquisition. Wiley Interdisciplinary Reviews: Cognitive Science $\mathbf{I}(6)$, 906-I 4.

Rondal, J.-A. \& Docquier, L. (2006). Maternal speech to children with Down syndrome: an update. Fournal of Speech-Language Pathology and Applied Behavior Analysis I(3), 2 I 8-27.

Rose, D. H., Slater, A. \& Perry, H. (I986). Prediction of childhood intelligence from habituation in early infancy. Intelligence $\mathbf{1 0}(3), 25 \mathrm{I}-63$. 
Rosenblum, L. D., Schmuckler, M. A. \& Johnson, J. A. (1997). The McGurk effect in infants. Perception \& Psychophysics 59(3), 347-57.

Rubenstein, J. L. R. \& Merzenich, M. M. (2003). Model of autism: increased ratio of excitation/inhibition in key neural systems. Genes, Brain and Behavior 2, 255-67.

Ruddy, M. G. \& Bornstein, M. H. (1982). Cognitive correlates of infant attention and maternal stimulation over the first year of life. Child Development 53, i $83-8$.

Ruff, H. A., Capozzoli, M. \& Weissberg, R. (1998). Age, individuality, and context as factors in sustained visual attention during the preschool years. Developmental Psychology 34(3), 454-64.

Ruff, H. A. \& Lawson, K. R. (1990). Development of sustained, focused attention in young children during free play. Developmental Psychology 26(I), 85-93.

Saffran, J. R., Aslin, R. N. \& Newport, E. L. (1996). Statistical learning by 8-month-old infants. Science 274, I926-8.

Saffran, J. R. \& Wilson, D. P. (2003). From syllables to syntax: multilevel statistical learning by 12 -month-old infants. Infancy 4(2), 273-84.

Sahni, S. D., Seidenberg, M. S. \& Saffran, J. R. (2010). Connecting cues: overlapping regularities support cue discovery in infancy. Child Development 81(3), 727-36.

Samuelson, L. K., Kucker, S. C. \& Spencer, J. P. (2017). Moving word learning to a novel space: a dynamic systems view of referent selection and retention. Cognitive Science $\mathbf{4 I}$ (SI), 52-72.

Samuelson, L. K. \& McMurray, B. (2016). What does it take to learn a word? WIREs Cognitive Science. Doi: I0.1002/wcs. I $42 \mathrm{I}$.

Samuelson, L. K. \& Smith, L. B. (1998). Memory and attention make smart word learning: an alternative account of Akhtar, Carpenter, and Tomasello. Child Development 69, 94-104.

Sebastián-Gallés, N., Albareda-Castellot, B., Weikum, W. M. \& Werker, J. F. (2012). A bilingual advantage in visual language discrimination in infancy. Psychological Science $\mathbf{2 3}$ (9), 994-9.

Simmons, D. R., Robertson, A. E., McKay, L. S., Toal, E., McAleer, P. \& Pollick, F. E. (2009). Vision in autism spectrum disorders. Vision Research 49(22), 2705-39.

Sirois, S. \& Mareschal, D. (2004). An interacting systems model of infant habituation. Fournal of Cognitive Neuroscience 16, I352-62.

Smith, L. B. (2005). Cognition as a dynamic system: principles from embodiment. Developmental Review 25(3), 278-98.

Smith, L. B., Yu, C. \& Pereira, A. F. (20I I). Not your mother's view: the dynamics of toddler visual experience. Developmental Science I4(I), 9-I 7 .

Smith, S. L., Gerhardt, K. J., Griffiths, S. K., Huang, X. \& Abrams, R. M. (2003). Intelligibility of sentences recorded from the uterus of a pregnant ewe and from the fetal inner ear. Audiology and Neurotology 8(6), 347-53.

Sokolov, Y. N. (1963). Perception and the conditioned reflex. New York, NY: Macmillan.

Soukup-Ascençao, T., D’Souza, D., D’Souza, H. \& Karmiloff-Smith, A. (20r6). Parentchild interaction as a dynamic contributor to learning and cognitive development in typical and atypical development. Infancia y Aprendizaje, 39(4), 694-726.

Spencer, J. P., Thomas, M. S. C. \& McClelland, J. L. (Eds.) (2009). Toward a unified theory of development: connectionism and dynamic systems theory re-considered. New York, NY: Oxford University Press.

Stiles, J. (2008). The fundamentals of brain development: integrating nature and nurture. Cambridge, MA: Harvard University Press.

Streeter, L. A. (1976). Language perception of 2-mo-old infants shows effects of both innate mechanisms and experience. Nature 259(5538), 39-4I.

Striano, T. \& Stahl, D. (2005). Sensitivity to triadic attention in early infancy. Developmental Science 8(4), 333-43.

Sumby, W. H. \& Pollack, I. (I954). Visual contribution to speech intelligibility in noise. Fournal of the Acoustical Society of America 26(2), 212-5. 


\section{D'SOUZA $E T A L$.}

Tamis-LeMonda, C. S. \& Bornstein, M. H. (I989). Habituation and maternal encouragement of attention in infancy as predictors of toddler language, play, and representational competence. Child Development 6o, 738-5I.

Teinonen, T., Aslin, R. N., Alku, P. \& Csibra, G. (2008). Visual speech contributes to phonetic learning in 6-month-old infants. Cognition Io8(3), 850-5.

Teinonen, T., Fellman, V., Näätänen, R., Alku, P. \& Huotilainen, M. (2009). Statistical language learning in neonates revealed by event-related brain potentials. $B M C$ Neuroscience $\mathbf{1 0}(\mathrm{I}), 2 \mathrm{I}$.

Thiessen, E. D. \& Saffran, J. R. (2007). Learning to learn: infants' acquisition of stress-based strategies for word segmentation. Language Learning and Development 3(I), 73-100.

Tomasello, M. \& Todd, J. ( 1983 ). Joint attention and lexical acquisition style. First Language 4, I97-2 I I.

Tremblay, M. C. \& Sabourin, L. (2012). Comparing behavioral discrimination and learning abilities in monolinguals, bilinguals and multilinguals. Fournal of the Acoustical Society of America 132(5), 3465-74.

Trevarthen, C. \& Hubley, P. (1978). Secondary intersubjectivity: confidence, confiding and acts of meaning in the first year. In A. Lock (ed.), Action, gesture and symbol: the emergence of language, I 83-229. New York, NY: Academic Press.

Tsao, F. M., Liu, H. M. \& Kuhl, P. K. (2004). Speech perception in infancy predicts language development in the second year of life: a longitudinal study. Child Development 75(4), 1067-84.

Ulrich, B. D. (2010). Opportunities for early learning intervention based on theory, basic neuroscience, and clinical science. Physical Therapy 9o(г 2), i 868-80.

Ulrich, B. D. \& Ulrich, D. A. (I 993). Dynamic systems approach to understanding motor delay in infants with Down syndrome. Advances in Psychology 97, 445-59.

Ulrich, D. A., Ulrich, B. D., Angulo-Kinzler, R. M. \& Yun, J. (200I). Treadmill training of infants with Down syndrome: evidence-based developmental outcomes. Pediatrics 1o8(5), e84.

Walle, E. A. \& Campos, J. J. (20I4). Infant language development is related to the acquisition of walking. Developmental Psychology 5o(2), 336-48.

Werker, J. F. (1986). The effect of multilingualism on phonetic perceptual flexibility. Applied Psycholinguistics $7(2), \mathrm{I} 4 \mathrm{I}-55$.

Werker, J. F. \& Byers-Heinlein, K. (2008). Bilingualism in infancy: first steps in perception and comprehension. Trends in Cognitive Sciences I2(4), I 44-5 I.

Werker, J. F. \& Tees, R. C. ( I 984). Cross-language speech perception: evidence for perceptual reorganization during the first year of life. Infant Behavior and Development 7(I), 49-63.

Werker, J. F., Yeung, H. H. \& Yoshida, K. A. (2012). How do infants become experts at native-speech perception? Current Directions in Psychological Science 2I(4), 22 I-6.

Wiig, E. H., Secord, W. \& Semel, E. M. (1992). Clinical evaluation of language fundamentals preschool, San Antonio, TX: The Psychological Corporation.

Williams, J. L., Corbetta, D. \& Guan, Y. (2015). Learning to reach with 'sticky' or 'nonsticky' mittens: a tale of developmental trajectories. Infant Behavior and Development 38, $82-96$.

Woodward, A. L. \& Markman, E. M. (I998). Cognition, perception, and language. In D. Kuhn \& R. S. Siegler (eds), Handbook of Child Psychology, vol. 2, 371-420. Hoboken, NJ: John Wiley \& Sons.

Xu, F. \& Tenenbaum, J. B. (2007). Word learning as Bayesian inference. Psychological Review II4(2), 245-72.

Yu, C. \& Smith, L. B. (2013). Joint attention without gaze following: human infants and their parents coordinate visual attention to objects through eye-hand coordination. PLoS ONE 8 (I I), e79659.

Yu, C. \& Smith, L. B. (2016). The social origins of sustained attention in one-year-old human infants. Current Biology, 26(9) I 235-1240. 
Yu, C., Smith, L. B., Shen, H., Pereira, A. F. \& Smith, T. (2009). Active information selection: visual attention through the hands. IEEE Transactions on Autonomous Mental Development $\mathbf{I}(2)$, I $4 \mathrm{I}-5 \mathrm{I}$.

Zampini, L., Fasolo, M. \& D'Odorico, L. (2012). Characteristics of maternal input to children with Down syndrome: a comparison with vocabulary size and chronological agematched groups. First Language 32(3), 324-42.

Zimmerman, I. L., Steiner, V. G. \& Pond, R. E. (1992). Preschool language scale-3, New York, NY: The Psychological Corporation.

Zoghbi, H. Y. (2003). Postnatal neurodevelopmental disorders: meeting at the synapse? Science 302(5646), 826-30. 